\title{
Modulation of Specific and Allergy-Related Immune Responses by Helminths
}

\author{
Emilia Daniłowicz-Luebert, Noëlle L. O’Regan, Svenja Steinfelder, and Susanne Hartmann
}

Department of Molecular Parasitology, Humboldt University of Berlin, Philippstraße 13, Building 14, 10115 Berlin, Germany

Correspondence should be addressed to Susanne Hartmann, susanne.hartmann@hu-berlin.de

Received 15 July 2011; Accepted 9 September 2011

Academic Editor: Luis I. Terrazas

Copyright () 2011 Emilia Daniłowicz-Luebert et al. This is an open access article distributed under the Creative Commons Attribution License, which permits unrestricted use, distribution, and reproduction in any medium, provided the original work is properly cited.

\begin{abstract}
Helminths are master regulators of host immune responses utilising complex mechanisms to dampen host protective Th2-type responses and favour long-term persistence. Such evasion mechanisms ensure mutual survival of both the parasite and the host. In this paper, we present recent findings on the cells that are targeted by helminths and the molecules and mechanisms that are induced during infection. We discuss the impact of these factors on the host response as well as their effect in preventing the development of aberrant allergic inflammation. We also examine recent findings on helminth-derived molecules that can be used as tools to pinpoint the underlying mechanisms of immune regulation or to determine new anti-inflammatory therapeutics.
\end{abstract}

\section{Introduction: Features of Helminth-Induced Immune Responses}

Helminths have developed a unique evolutionary dialogue with their hosts' immune system due to their longevity within the host, their complex life cycles, and multicellular nature. These pathogens induce very different immune responses in comparison to bacteria, fungi, viruses, or protozoa. Cells of the innate and adaptive immune system are important for the initiation of type 2 immunity, which characterises the response to helminth infection, as well as allergic reactions. The key players in T helper (Th) 2-type immunity are $\mathrm{CD} 4^{+} \mathrm{Th} 2$ cells and involve the cytokines interleukin (IL-)4, IL-5, IL-9, IL-10, and IL-13 and immunoglobulin (Ig)E. CD4 ${ }^{+}$Th2 cells also express some of the cytokines mentioned above as well as the chemokine ligand CCL11 and the chemokine receptor CCR3 [1-3]. These factors lead to recruitment and infiltration of eosinophils, basophils and mast cells, and expansion of alternatively activated macrophages [4]. Notably, Th2-type immune responses are composed of three major features: inflammation, wound repair, and, most importantly, resistance to helminths.

Parasites have developed various strategies to modulate the immune system and ultimately suppress host protective Th2-type immune responses for example, by induction of innate and adaptive regulatory cells, anti-inflammatory cytokines and specific inhibitory antibody isotypes (reviewed by Anthony et al. [2]).

Hence, helminth parasites are master regulators of immune responses in order to ensure life-long persistence in the host. One strategy of immune regulation that has evolved is the secretion of a wide range of immunoregulatory molecules, which are able to target various host cells and alter them to induce a highly directed host response known as a "modified Th2-type response." This response is designed to limit a possibly detrimental Th2 immune response, thus restraining the extreme symptoms that are often observed in allergy or in aspects of helminth diseases such as fibrosis in Schistosoma mansoni [3]. In immunological terms, the modified Th2 response is defined by the development of specific antibody isotypes, including induction of IgG4 accompanied by a decrease in IgE, as well as IL- 4 and IL-5, while IL10 levels from different regulatory cell sources increase [5]. These mechanisms can lead to attenuation of pathology and clinical symptoms, tolerance, and ultimately persistence of the worm, which is associated with a hyporesponsive immune system. Asymptomatic infection assures long-term survival of the parasite within the host and therefore sustains parasite feeding, completion of the life cycle, and successful reproduction $[3,5]$. 
Many studies of animal and human helminth infections have shown their potential for downregulating the immune system. Moreover, relevant epidemiological studies have observed that helminth-infected populations exhibit lower levels of immunopathological diseases such as Th1-related autoimmune diseases or abberrant Th2-related diseases for example, asthma or allergic rhinitis. These observations indicate an inverse global distribution of allergy/autoimmune diseases and helminth infections, the first being an expanding problem of developed and industrialized countries, while the latter being a feature in developing countries [6-9]. Such findings support the hypothesis that the immune system has coevolved to operate in the presence of immunomodulatory helminth infections, while in the absence of exposure to helminths, the immunoregulatory components that would normally prevent allergy and autoimmune disease become weakened $[5,10]$.

Here, we focus on recent advances in cellular mechanisms that are employed and modulated during helminth infections as well as on reports from field research and studies on animal models. These studies have identified helminths and helminth-derived products that play a role either in induction of Th2 responses and immune modulation in parasitic infections (reviewed in Table 1) or in downregulation of bystander Th2-type immunopathologies like allergic asthma, allergic inflammation and airway hyperreactivity, food allergy, eczema, atopic dermatitis (Th1/Th2), or anaphylaxis (reviewed in Table 2).

\section{Epidemiological Evidence of Helminth-Induced Immunoregulation}

2.1. Immunoregulation during Helminth Infection in Humans. It has long been known that helminths induce a specific immune phenotype in the majority of persons that allows for establishment of infection while simultaneously preventing or reducing signs of disease in the host [11]. Antigenspecific cellular hyporesponsiveness was described for filarial infections more than 30 years ago by Ottesen et al. studying a population in the Cook Islands endemic for lymphatic filariasis. In this study lymphocytes from adults infected with the filarial species Wuchereria bancrofti showed significantly lower levels of proliferation in response to filarial antigen compared with endemic controls who were negative for all signs of infection or disease but constantly exposed to infection and, therefore, putatively consistently exposed to the antigens [12]. Later, another study from the same group made the distinction between microfilariae (mf) positive asymptomatically infected persons and $\mathrm{mf}$ negative patients showing clinical symptoms of filariasis (e.g., elephantiasis or hydrocoele) [13]. The resulting data suggested that the outcome of disease depends on the host response together with a mechanism of immune modulation induced by the parasite (reviewed by Ottesen [14]). Epidemiological studies of helminth-infected persons recognise distinct clinical outcomes that depend on immune regulation induced by the parasite in conjunction with the genetic background of the host (reviewed by Maizels and Yazdanbakhsh [3]). Resistant individuals are constantly exposed to the parasite but show no signs of infection or disease; this group develops an appropriate response, defined by equal proportions of Th1, Th2, and T regulatory (Treg) cells with a balance of IgG4 and IgE levels. A second group develops a hyporesponsive phenotype characterised by asymptomatic infection, which tolerates the presence of fecund adult worms. This group has high levels of regulatory cells and IL-10, leading to a modified Th2 response. Finally, a small proportion of patients develops a hyperresponsive phenotype (characterised by an immunopathological response) $[3,11,14]$. In S. mansoni, $W$. bancrofti, and Brugia malayi infections, the main pathological response is a result of overreactive $\mathrm{T}$ cell responses that cause inflammation and injure the host. This group exhibits increased IgE responses, and the Treg compartment is greatly diminished. In W. bancrofti and B. malayi infections, this can result in elephantiasis, whereby the lymphatic tissue becomes dilated and hypertrophic. Parasite death leads to the release of antigenic material that causes lymphatic obstruction in the vessels and chronic inflammation [14]. A second, rare result of these infections is tropical pulmonary eosinophilia characterised by chronic lung obstruction, peripheral blood eosinophilia, and extremely elevated levels of IgE, greater than in elephantiasis [15]. In Onchocerca volvulus infection the rare chronic hyperreactive form, known as Sowda, is also defined by high levels of IgE [16]. This is accompanied by strong Th2 responses, including IL-4, IL-5, and IL-13. Thus a fine balance of different aspects of immunity is required to develop a response beneficial to the host.

Therefore, immune modulation acts in favour of persistent infection and continuous transmission while simultaneously enabling the host to tolerate infection by diminishing clinical symptoms. Coinfection studies of helminths with other diseases provide supporting evidence that helminths have great ability to modulate immune responses, some aspects of which may then affect bystander infections. In fact, protective inflammatory immune responses that typically develop in bacterial or intracellular parasitic infections can be downregulated when a coinfecting helminth is present, resulting in increased susceptibility in the host to the former infection. For example, individuals coinfected with latent tuberculosis (TB) and W. bancrofti showed lower levels of TB-protective proinflammatory cytokines in vitro than TB patients without filarial infection. This effect was reversed after treatment with microfilaricidal drugs [47]. Research focusing on individuals coinfected with multiple filarial species and Plasmodium falciparum demonstrated a modulation of the antimalarial immune response by helminths that increased anti-inflammatory responses [48]. After stimulation with malaria antigen, filarial-infected individuals demonstrated significantly lower levels of interferon (IFN)- $\gamma$, tumour necrosis factor (TNF)- $\alpha$ and IL-17A, and higher levels of IL-10 from CD4 ${ }^{+} \mathrm{T}$ cells compared with filarial-uninfected individuals. Similarly, a study examining the effect of helminth infections on responses to oral cholera vaccine demonstrated that Ascaris lumbricoides infection was associated with lower cholera antigen-specific IL-2 cytokine responses [49]. These epidemiological studies demonstrate the ability of helminths to modulate immune responses to themselves as well as to concurring and unrelated infections. 
TABle 1: Helminth-derived immunomodulatory and Th2-inducing molecules. CXCL: chemokine ligand; DC: dendritic cell; Ig: immunoglobulin; GI: gastrointestinal; IFN- $\gamma$ : interferon gamma; IL: interleukin; LPS: lipopolysaccharide; MAP: mitogen activated kinase; MHC: major histocompatibility complex; MIF: macrophage migration inhibitory factor; PBMC: peripheral blood mononuclear cell; STAT: signal transducer and activator of transcription; TGF: transforming growth factor; Th: T helper cell; TLR: Toll-like receptor; Treg: T regulatory cell.

\begin{tabular}{|c|c|c|c|c|}
\hline Helminth species & Name & Molecule & $\begin{array}{l}\text { Mechanisms of immune modulation during } \\
\text { infection }\end{array}$ & Reference \\
\hline $\begin{array}{l}\text { Echinococcus } \\
\text { granulosus }\end{array}$ & $\mathrm{AgB}$ & Antigen B & $\begin{array}{l}\text { Reduces expression of costimulatory molecules on } \\
\text { human DCs and induces Th2 }\end{array}$ & {$[17]$} \\
\hline Fasciola hepatica & FheCL1 & Cysteine protease & $\begin{array}{l}\text { Prevents release of macrophage inflammatory } \\
\text { mediators by degrading TLR } 3\end{array}$ & {$[18]$} \\
\hline \multirow{5}{*}{ Schistosoma mansoni } & Lyso-PS & Lyso-phosphatidylserine & $\begin{array}{l}\text { Lyso-PS treated DCs induce IL- } 10^{+} \text {Treg through } \\
\text { TLR2 and promote Th2 polarization }\end{array}$ & {$[19,20]$} \\
\hline & DsRNA & Double-stranded RNA & $\begin{array}{l}\text { Triggers TLR } 3 \text { to activate STAT1 and induces } \\
\text { expression of type } 1 \text { IFNs in DCs }\end{array}$ & {$[21,22]$} \\
\hline & Omega-1 & Ribonuclease & $\begin{array}{l}\text { Reduces expression of costimulatory molecules and } \\
\text { IL-12 in DCs and induces IL- } 4 \text { and Foxp } 3 \text { in CD } 4^{+} \\
\text {cells }\end{array}$ & [23-25] \\
\hline & IPSE/alpha-1 & Glycoprotein & $\begin{array}{l}\text { Induces IgE-dependent IL-4 production from } \\
\text { basophils in vivo }\end{array}$ & {$[26]$} \\
\hline & SmCKBP & $\begin{array}{l}\text { Chemokine-binding } \\
\text { protein }\end{array}$ & $\begin{array}{l}\text { Suppresses neutrophil recruitment by inhibiting the } \\
\text { mammalian chemokine CXCL8 }\end{array}$ & {$[27]$} \\
\hline Ascaris suum & PAS-1 & $200 \mathrm{kDa}$ protein & $\begin{array}{l}\text { Suppresses proinflammatory cytokines and } \\
\text { neutrophil influx after exposure to LPS }\end{array}$ & {$[28]$} \\
\hline \multirow[b]{2}{*}{ Necator americanus } & $\mathrm{Na}$-ASP-2 & $\begin{array}{l}\text { High homology to C-C } \\
\text { chemokines }\end{array}$ & $\begin{array}{l}\text { Secreted by infective larvae, recruits neutrophils in } \\
\text { vitro and in vivo }\end{array}$ & {$[29]$} \\
\hline & $\mathrm{Na}$-NES & Metalloprotease & $\begin{array}{l}\text { Cleaves the eosinophil chemoattractant CCL11 and } \\
\text { prevents its action in vitro and in vivo }\end{array}$ & {$[30]$} \\
\hline $\begin{array}{l}\text { Nippostrongylus } \\
\text { brasiliensis }\end{array}$ & Acetylhydrolase & Acetylhydrolase & $\begin{array}{l}\text { Inactivates mammalian platelet-activating factor, } \\
\text { thus potentially regulating GI inflammation }\end{array}$ & {$[31]$} \\
\hline Trichinella spiralis & $T s$-MIF & MIF homologue & $\begin{array}{l}\text { Inhibits migration of human PBMCs, similar to } \\
\text { human MIF }\end{array}$ & {$[32]$} \\
\hline Trichuris muris & $\begin{array}{l}43 \mathrm{kDa} \text { IFN- } \gamma \\
\text { homologue }\end{array}$ & IFN- $\gamma$ homologue & Binds to IFN- $\gamma$ receptor in mice & {$[33]$} \\
\hline \multirow[b]{2}{*}{$\begin{array}{l}\text { Acanthocheilonema } \\
\text { viteae }\end{array}$} & AvCystatin /Av17 & $\begin{array}{l}\text { Cysteine protease } \\
\text { inhibitor }\end{array}$ & $\begin{array}{l}\text { Downregulates T cell responses. Interferes with } \\
\text { macrophage MAP kinase signaling pathways to } \\
\text { induce IL-10 }\end{array}$ & {$[34,35]$} \\
\hline & ES-62 & $\begin{array}{l}\text { Phosphorylcholine- } \\
\text { containing } \\
\text { glycoprotein }\end{array}$ & $\begin{array}{l}\text { Reduces CD } 4^{+} \mathrm{T} \text { cell proliferation and IL- } 2 \\
\text { production, inhibits IL- } 4 \text { and IL- } 13 \text { production } \\
\text { Inhibits IL-12 production from macrophages after } \\
\text { exposure to LPS in a TLR4-dependent manner } \\
\text { Induces an anti-inflammatory phenotype in DCs }\end{array}$ & [36-39] \\
\hline \multirow{3}{*}{ Brugia malayi } & $\begin{array}{l}\text { Bm-ALT-1, } \\
\text { Bm-ALT-2 }\end{array}$ & $\begin{array}{l}\text { Abundant larval } \\
\text { transcript proteins }\end{array}$ & $\begin{array}{l}\text { Expression of Bm-ALT in recombinant Leishmania } \\
\text { mexicana parasites diminishes IFN- } \gamma \text {-mediated } \\
\text { killing and induces GATA-3 and SOCS- } 1 \text { in these } \\
\text { macrophages }\end{array}$ & {$[40]$} \\
\hline & $B m$-CPI-2 & $\begin{array}{l}\text { Cysteine protease } \\
\text { inhibitor }\end{array}$ & $\begin{array}{l}\text { Blocks antigen presentation via MHC class II by } \\
\text { interfering with asparaginyl endopeptidase }\end{array}$ & {$[41,42]$} \\
\hline & Bm-TGH-2 & Homologue of TGF- $\beta$ & $\begin{array}{l}\text { Binds to mammalian TGF- } \beta \text { receptors thus } \\
\text { potentially influencing Treg differentiation }\end{array}$ & {$[43]$} \\
\hline $\begin{array}{l}\text { Litomosoides } \\
\text { sigmodontis }\end{array}$ & Ls-cystatin & $\begin{array}{l}\text { Cysteine protease } \\
\text { inhibitor }\end{array}$ & Reduces antigen-specific proliferation of spleen cells & {$[44]$} \\
\hline Onchocerca volvulus & Onchocystatin & $\begin{array}{l}\text { Cysteine protease } \\
\text { inhibitor }\end{array}$ & $\begin{array}{l}\text { Suppresses antigen-specific proliferation of PBMCs, } \\
\text { induces IL-10 from stimulated PBMCs } \\
\text { Reduces expression of MHC class II molecules and } \\
\text { CD86 on human monocytes }\end{array}$ & {$[45,46]$} \\
\hline
\end{tabular}


TABLE 2: Effects of helminth infections and helminth-derived products/molecules on improvement of symptoms in allergy-related experimental animal models.

\begin{tabular}{|c|c|c|c|}
\hline & Allergy model & Suppressive mechanism & Reference \\
\hline \multicolumn{4}{|c|}{ Defined helminth molecules; (from helminth species) } \\
\hline smCKBP; (S. mansoni) & $\begin{array}{l}\text { Hapten-induced contact } \\
\text { hypersensitivity }\end{array}$ & $\mathrm{NA}^{3}$ & {$[27]$} \\
\hline $\begin{array}{l}\text { Sm22.6, PIII and Sm29; }(S . \\
\text { mansoni) }\end{array}$ & OVA-induced $\mathrm{AI}^{1}$ & $\mathrm{CD}^{+} \mathrm{Foxp}^{+}$Treg & {$[65]$} \\
\hline As-MIF; (A. simplex) & OVA-induced AI & IL-10, TGF- $\beta$, and Treg dependent & {$[66]$} \\
\hline \multirow{2}{*}{ PAS-1; (A. suum) } & APAS-3-induced AI & Possibly IL-10 & {$[67]$} \\
\hline & OVA-induced AHR ${ }^{2}$ & $\begin{array}{l}\mathrm{CD}^{+}{ }^{+} \mathrm{CD} 25^{+} \mathrm{T} \text { cell-, } \mathrm{CD} 8^{+} \mathrm{T} \text { cell-dependent and } \\
\text { IL-10/TGF- } \beta-\text { - IFN- } \gamma \text {-mediated }\end{array}$ & {$[68,69]$} \\
\hline $\begin{array}{l}\text { Nippocystatin (NbCys); }(\mathrm{N} . \\
\text { brasiliensis) }\end{array}$ & OVA-induced AI & Cathepsin B and cathepsin L-dependent mechanism & {$[70]$} \\
\hline AvCystatin (Av17); (A. viteae) & OVA-induced AHR & IL-10, macrophages, partially $\mathrm{CD} 4^{+} \mathrm{CD} 25^{+} \mathrm{T}$ cells & [71] \\
\hline ES-62; (A. viteae) & $\begin{array}{l}\text { Oxazolone- (Oxa-) induced skin } \\
\text { immediate hypersensitivity } \\
\text { OVA-induced AHR }\end{array}$ & Mast cell mediated, TLR4-dependent & {$[72]$} \\
\hline \multicolumn{4}{|c|}{ Helminth infection and undefined products } \\
\hline $\begin{array}{l}\text { S. mansoni infection; males and } \\
\text { females + eggs laid in infection; } \\
\text { males (no eggs) }\end{array}$ & Pen V-induced systemic anaphylaxis & IL-10-producing B cells & {$[73]$} \\
\hline $\begin{array}{l}\text { S. mansoni infection; males (no } \\
\text { eggs) }\end{array}$ & OVA-induced AHR & $\begin{array}{l}\text { B cell- and IL-10-dependent suppression of pulmonary } \\
\text { eosinophil infiltration }\end{array}$ & {$[74]$} \\
\hline S. mansoni infection; eggs & OVA-induced AI & Egg-treatment: $\mathrm{CD} 4^{+} \mathrm{CD} 25^{+}$Foxp $3^{+}$Treg & {$[75]$} \\
\hline S. japonicum egg antigen (SEA) & OVA-induced AI & $\mathrm{CD}^{+}{ }^{+} \mathrm{CD} 25^{+}$Treg, possibly IL-10 & {$[76]$} \\
\hline $\begin{array}{l}\text { A. suum adult worm extract } \\
\text { (ASC) }\end{array}$ & OVA-induced AHR & NA & {$[77]$} \\
\hline \multirow{3}{*}{$\begin{array}{l}\text { Heligmosomoides } \\
\text { polygyrus infection }\end{array}$} & OVA-induced AHR & IL-10 & {$[78]$} \\
\hline & $\begin{array}{l}\text { OVA-induced AHR } \\
\text { HDM-induced AI }\end{array}$ & $\begin{array}{l}\text { IL-10-independent, CD } 4^{+} \mathrm{CD} 25^{+} \mathrm{T} \text { cells } \\
\text { IL-10-independent Breg cells }\end{array}$ & {$[79,80]$} \\
\hline & Peanut extract-induced food allergy & IL-10 & {$[81]$} \\
\hline $\begin{array}{l}\text { H. polygyrus excretory-secretory } \\
\text { product (HES) }\end{array}$ & OVA-induced AI & HES-induced Treg cells & {$[82]$} \\
\hline N. brasiliensis infection & OVA-induced AHR & IL-10 from unknown cell source & {$[83]$} \\
\hline \multicolumn{2}{|c|}{$\begin{array}{l}\text { N. brasiliensis excretory-secretory } \mathrm{OVA} \text {-induced AI } \\
\text { product (NES) }\end{array}$} & NA (IL-10 independent) & {$[84]$} \\
\hline \multicolumn{2}{|c|}{ Strongyloides stercoralis infection OVA-induced AI } & NA & {$[85]$} \\
\hline $\begin{array}{l}\text { Strongyloides venezuelensis } \\
\text { infection }\end{array}$ & OVA-induced AI & NA & {$[86]$} \\
\hline T. spiralis infection & OVA-induced AI & $\begin{array}{l}\text { Correlated with increased IL-10, TGF- } \beta, \mathrm{CD} 4^{+} \mathrm{CD} 25^{+} \\
\text {Treg }\end{array}$ & {$[87]$} \\
\hline L. sigmodontis infection & OVA-induced AHR & TGF- $\beta, \mathrm{CD}^{+} \mathrm{CD} 25^{+}$Treg & {$[88]$} \\
\hline \multicolumn{4}{|c|}{$\begin{array}{l}1 \text { (AI): airway inflammation, associated with inflammatory cell influx into the lungs and local Th2 cytokine production. } \\
2 \text { (AHR): airway hyperreactivity, mainly described as lung bronchiole and smooth-muscle tissue remodelling leading to airflow obstruction, resulting in } \\
\text { altered airway function. Chronic airway inflammation may lead to AHR, however, different immunopathological pathways govern the regulation of AI and } \\
\text { AHR (discussed elsewhere [89-93]). } \\
{ }^{3} \text { NA data not available. }\end{array}$} \\
\hline
\end{tabular}

2.2. Inverse Correlation between Helminth Infections and Allergic Reactions. Eradication of helminth infections in industrialised countries in the past 30 years has had a great impact on the prevalence of diseases associated with inappropriate immune responses. The observed increase in the appearance of allergy-related diseases might be a result of this and altered hygienic measures in everyday life. One possible explanation is the hygiene hypothesis $[50,51]$, which includes a number of factors like improved public health, use of antibiotics and vaccines that in consequence reduce the occurrence of viral, bacterial or helminth infections early in life, contributing to higher numbers of individuals with allergic, and/or autoimmune disorders.

There are numerous cohort studies determining allergic disease status and immune responses to parasite-specific antigens or environmental allergens of helminth-infected 
individuals in parasite-endemic areas (reviewed by others $[6,8])$. However, when interpreting this data it is important to take into consideration the time of first infection, duration and intensity of infection, helminth species, as well as host genetic and environmental factors.

Infections with trematodes, whipworms and hookworms were described to be negatively correlated with the allergen skin prick test [52]. Results from a study of Gabonese school children tested for skin reaction to house dust mites (HDMs) and other allergens, for Schistosoma eggs in urine and microfilariae of Loa loa and Mansonella perstans in blood, showed lower prevalence of a positive skin test to HDMs in children with urinary schistosomiasis. Moreover, schistosome antigen-specific concentrations of IL-10 were significantly higher in infected children and concentrations of IL-10 were negatively associated with a positive skin test result [53].

Several population studies done in endemic areas of Schistosoma infections in Brazil [54,55] and of Ascaris, Trichuris, and Ancylostoma in Ecuador [56] revealed a strong inverse association between helminth infections and immediate skin test reactivity to common environmental aeroallergens. Araujo et al. [54] and Cooper et al. [56] reported a negative association between very high levels of IgE antibodies and allergen skin test reactivity. It is possible that antihelminth-IgE competes for the same high-affinity IgE receptors targeted by allergen-specific IgE [54]. Although other studies from Africa reported on a reverse association between hookworm infections and sensitization to HDM Dermatophagoides pteronissinus (Der p 1), they did not show a significant association between skin test sensitivity to HDMs, allergen-specific IgEs and between total serum IgE levels and helminth-specific IgEs $[57,58]$.

The contribution of helminth infections to the inverse correlation with allergy-related diseases was demonstrated in studies with anthelminthic treatment. Results from a randomized, controlled trial on the effect of repeated treatment with anthelminthics on a population of Gabonese school children showed a significant increase in the rate of developing skin sensitivity to HDMs. This was in part mediated by reductions of Ascaris and/or Trichuris infections, directly pointing to the importance of a presence of live worms to suppress allergic responses during infection and also preventing allergy later in life [59]. Lynch et al. also reported an effect of anthelminthic treatment on the allergic reactivity of children in the tropics in Venezuela. The authors showed that the effective elimination of intestinal helminth infection resulted in significantly decreased total serum IgE levels. However, immediate-hypersensitivity skin test reactivity and serum levels of specific IgE antibody against common allergens were significantly increased in treated children [60]. Also other studies reported that anthelminthic treatments increase allergen skin reactivity to environmental allergens $[61,62]$. Rodrigues et al. reported that Brazilian children with heavy infection in early childhood with Trichuris trichiura had a lower prevalence of allergen skin test reactivity to a wide spectrum of common environmental allergens (HDMs, Blomia tropicalis, fungi, animal, and cockroach allergens) later in childhood, even when the helminth infection was no longer present [63]. Additionally, a population study in
Taiwan showed that schoolchildren bearing pinworm Enterobius were diagnosed with lower prevalence of asthma and allergic rhinitis; moreover, these children had reported an infection of pinworms early on in life [64]. Thus, early exposures and infections with helminths may have a protective effect and suppress allergic inflammation later during life.

Additionally, host genetic factors may play a role in prevalence of helminth infections and allergies. Notably variants of genes involved in Th2 immune responses like IL13 or STAT6 were associated with increased risk of asthma and allergy [94-97]. Studies among African-Americans shed a light on the limited understanding we have on asthma genetics. Polymorphisms in candidate genes associated with asthma showed higher frequency among certain ethnic backgrounds that developed strong Th2 immune responses $[6,98,99]$. Thus, genes, which in the evolution of the immune system were initially responsible for induction of Th2-type immune responses and for parasite expulsion, now cause problems with allergy-related diseases when living in "sterile" and modern societies.

2.3. Helminth Infections that Promote Allergic Reactions. In contrast to population studies reporting a negative correlation between allergy and helminth infections as discussed above, various studies from South America, Europe, and Asia on A. lumbricoides infections and allergy reported increased rather than decreased prevalence of asthma [100-102]. For example, two cross-sectional surveys among schoolchildren in former East Germany revealed that children with low doses of helminthic antigens (low worm burden) but AscarisIgE seropositivity had higher levels of total $\operatorname{IgE}$ and higher prevalence of allergic rhinitis and asthma to inhalant allergens [101]. It was proposed that heavy parasitic infections might generate immune suppressive mechanisms, whereas mild worm exposure and low-level contact with helminths may enhance reactivity to environmental allergens or even potentiate the Th2 immune response that in some cases may promote allergic inflammation. As Ascaris infection has been well-documented as a risk factor for asthma (described elsewhere [103-106]), there are two main hypotheses why Ascaris promotes allergic reactions. The first relates to the specific pulmonary phase in the Ascaris life cycle that causes inflammation and eosinophilia, which results in IgEmediated asthma with high total- and specific-IgE titres against larvae and adult worms [107]. The second hypothesis of increased allergy in Ascaris infection is explained by crossreactivity of Ascaris-specific molecules with environmental allergens like HDMs or the storage mites B. tropicalis that induce allergen-specific IgEs leading to strong Th2-type responses and therefore contributing to overall pathogenesis [108]. Moreover, Ascaris-tropomyosin, a pan allergen, induced wheal and flare in skin prick tests and histamine release from basophils of asthmatics and nonasthmatics. These results suggest that Ascaris-tropomyosin in some allergic individuals potentiates the pathogenesis of asthma and other allergic diseases [109-111].

Interestingly, the promotion of atopy can also be observed in parasitic infections where the human is not the definitive host and, therefore, chronic infection is 
not established, for example, Toxocara spp. [52, 112]. In addition, the nematode Anisakis simplex, regularly infecting marine mammals as definitive hosts but accidentally also leading to gastrointestinal (GI) infections in humans, who ingest raw fish, was described to cause allergic reactions. Allergy to A. simplex is being recognised as an occupational disease with a wide spectrum of allergic reactions (rhinitis, asthma urticaria, allergic contact dermatitis, and anaphylactic shock) [113-115]. As both parasites cause accidental and infrequent infections, in case of infection the immune system may be exposed to Th2-inducing events rather than to immunomodulatory mechanisms that occur in chronic infections. These may contribute to the immune pathology and lead to allergic reactions.

It is important to keep in mind that variations in epidemiological studies may have many confounding factors like types of parasitic infections, intensity and timing of the infection, other coinfections, first exposure to allergen as compared to parasitic infection, types of allergens, nutritional status of the patients, medication received, and genetic background.

\section{Host Cells Targeted by Helminth Infections}

Current research has focused particularly on identifying the cells targeted by parasitic immune modulation, and the exact helminth-derived molecules responsible for this. Immune modulation by the parasite occurs through production of specific parasite-derived molecules that target mammalian host immune cells and signaling pathways. During infection this is strictly dependent on live parasites as shown by the recovery of cellular hyporesponsiveness in patients treated with anthelminthic chemotherapy [116]. In addition, a study by Da'dara and Harn demonstrated that killing of schistosome parasites could reinstate immune responses to a bystander vaccine targeting human immunodeficiency virus1 , which were greatly diminished in the presence of the parasite [117]. Similarly, another study demonstrated that prior elimination of intestinal helminths in patients vaccinated with bacille Calmette-Guerin resulted in greater protective responses to the vaccine compared with patients who did not receive anthelminthic chemotherapy [118]. During active infection, live worms are thus normally essential to ensure constant release of immunomodulatory molecules. Both GI and tissue-dwelling helminths can establish longterm chronic infections and have many immunomodulatory molecules in common, which, despite the different anatomical locations target similar host cells employing comparable regulatory mechanisms. Thus, experimental models together with human studies have helped to elucidate the mechanisms and cell targets underlying parasite-induced immune modulation. In this section, we discuss some of the most common and relevant examples.

3.1. Dendritic Cells. As professional antigen presenting cells (APCs) required in priming the adaptive immune response, dendritic cells (DCs) are an essential driving force of Th2 induction in helminth infections and in allergyrelated diseases. The field of research on DCs targeted by parasite-induced immune modulation is as vast as that on macrophages, and there is definitive evidence of a specific DC phenotype that develops in helminth infection, demonstrating modulation by the parasite to deviate host inflammatory responses. Several groups could show that in helminth infection, DCs mature only selectively or show impaired functions in terms of TLR responsiveness [119-122]. As DCs are the main messenger cells to communicate with $\mathrm{T}$ cells and initiate an immune response, interference with their functions represents a key mechanism for helminths to induce an environment conducive to their survival [123].

The downregulation of proinflammatory cytokines appears to be a frequent feature in helminth-mediated modulation of the Th2-type response [124]. Murine DCs stimulated with lipids from S. mansoni eggs matured to induce specifically Tregs that produced IL-10, reducing Th1 responses whilst producing a modulated Th2 response [19]. However, as reviewed by Carvalho et al. [124] DCs that have been previously exposed to helminth products can also effectively prime Th2 cells. S. mansoni soluble egg antigen (SEA) is a particularly strong inducer of Th2 responses, and importantly the glycoprotein omega-1 was identified as the main Th2-inducing component in SEA [23]. Human DCs exposed to B. malayi $\mathrm{mf}$ showed higher levels of apoptosis and decreased production of IL-12 and IL-10 [125]. In fact when human monocytes that were being differentiated to DCs in vitro were stimulated with $B$. malayi mf antigen, they produced significantly decreased levels of IL-12p40, IL12 p70, and IL-10 in response to bacterial adjuvant [121]. Massacand et al. also demonstrated how DCs exposed to excretory-secretory (ES) products from both Nippostrongylus brasiliensis and Heligmosomoides polygyrus had reduced expression of the proinflammatory cytokine IL-12/23p40 [126]. Similarly, Balic et al. reported that bone-marrowderived DCs exposed to $N$. brasiliensis ES (NES) products actively matured and could induce a Th2 response when transferred into naïve mice [119]. High levels of IL-4, IL-5, and IL-10 were detected after reexposure to NES. In vitro, these DCs produced high levels of IL- 6 and IL-12p40 but full production of IL-12p70 was blocked. Finally it was shown that murine lipopolysaccharide- (LPS-) or CpG-matured DCs exposed to ES products from Taenia crassiceps showed diminished responses to stimulation through TLRs 4 and 9. These DCs significantly decreased levels of proinflammatory cytokines, including IL-12p40 and IL-12p70, as well as TNF$\alpha$ and IL-15. IL-10 was, however not affected in this study [127]. Thus, downregulation of proinflammatory cytokines seems to be a frequent mechanism in immune modulation by helminths.

Combined with suppression of proinflammatory cytokines, a key aspect in modulation of DCs is the downregulation of costimulatory molecules, leading to induction of a Th2 response [124]. Dowling et al. illustrated that stimulation of murine bone-marrow-derived DCs with A. lumbricoides pseudocoelomic body fluid (ABF) influenced DC maturation by inducing expression of IL-6, IL-12p40, and macrophage inflammatory protein 2. However, DC maturation was only partial as levels of costimulatory molecules CD80, CD86, CD40, OX40L, and major histocompatibility 
complex (MHC) class II were not affected. Furthermore, when DCs were cultured in the presence of ovalbumin (OVA) with $\mathrm{ABF}$ and then transferred into naïve mice, restimulation resulted in significantly increased levels of IL4, IL-5, and IL-10 compared to DCs cultured without ABF [128]. Coculturing of ES products but not adult worm antigen from $H$. polygyrus with LPS-treated DCs induced a semimature phenotype with moderate expression of CD40, CD86, and MHC class II [120]. In fact when DCs were treated with ES and OVA and subsequently cultured with OVA-specific $\mathrm{T}$ cells, the $\mathrm{T}$ cells developed a regulatory phenotype, expressing CD25 and high levels of IL-10 [120]. Thus, targeted DCs could suppress both Th1 and Th2 responses. Furthermore, a novel subset of DCs expressing low levels of CD11c have also recently been identified in mice chronically infected with $H$. polygyrus [129]. In this infection setting, DCs acted as efficient APCs and induced high numbers of $\mathrm{CD}^{+} \mathrm{T}$ cells expressing Foxp3 but only low numbers of $\mathrm{CD}^{+}$effector T cells. This population of DCs was suggested to be one of the main target cells involved in inducing an immunoregulatory environment in $\mathrm{H}$. polygyrus infection, allowing the establishment of chronic infection [129]. Nevertheless, DCs are clearly essential for efficient priming of the Th2 response, as depletion of CD11 $\mathrm{c}^{+}$cells during development of the adaptive $\mathrm{CD} 4^{+} \mathrm{T}$ cell response in S. mansoni infection drastically impaired the Th2 response [130].

3.2. Alternatively Activated Macrophages. Macrophages that are activated by the Th2-type cytokines IL- 4 and IL-13 develop an alternatively activated phenotype and have a welldescribed role in helminth infections (reviewed by Hoerauf et al. [131]). Alternatively activated macrophages (AAMs) are recruited in large numbers to the sites of helminth infection where they can proliferate, as recently shown [4]. AAMs are characterised in mice by expression of specific markers, including arginase- 1 , resistin-like molecule (RELM)- $\alpha$ (also known as found in inflammatory zone, FIZZ1), Ym-1, Ym2, acidic mammalian chitinase (AMCase), and mannose receptor C type (MRC)-1 [132]. AAMs are important in tissue homeostasis, downregulation of the adaptive immune system, acting as effector cells against parasites, and to reduce or heal any ensuing damage caused by infection [133]. In particular, AAM-derived arginase-1 is important for wound healing [134]. AAMs recruited during B. malayi infection have been demonstrated to drive $\mathrm{CD}^{+}$Th2 responses, deviating the immune system from inducing a proinflammatory Th1 response that could be detrimental to parasite survival [135]. Monocytes from B. malayi asymptomatically infected patients have also been described to show an alternatively activated phenotype, expressing the AAMspecific markers arginase- 1, MRC- 1 , resistin, and CCL18 as well as the downregulatory cytokines transforming growth factor (TGF)- $\beta$ and IL-10 [136] (similar to what has been described for mouse AAMs [137]). However, translation of characterised markers into the human system in general should be done with caution, as reports indicate arginase1 may not be a reliable marker for AAMs in humans as it is found in other cell types [138]. Furthermore, human monocytes do not express arginase-1 after stimulation with IL-4 and IL-13, unlike mouse macrophages (reviewed by Raes et al. [139]). This indicates that the translation from murine to human data can be difficult, and reliable markers for alternative activation in human monocytes should be further investigated.

The importance of AAMs is clear from numerous mouse models. Macrophages from B. malayi infected mice were shown to be fully capable of processing and presenting antigen and providing costimulation for $\mathrm{T}$ cells, however the resulting antigen-specific $\mathrm{T}$ cell population remained suboptimal with cell proliferation but not Th2 cell cytokine production being impaired [140]. These macrophages were IL4-dependent and required direct contact with $\mathrm{T}$ cells to induce hyporesponsiveness [141]. In a mouse model of $S$. mansoni infection, arginase-expressing macrophages played an essential role in host protection by suppressing expression of the classical inflammatory cytokines IL-12 and IL23 [142]. Removal of these cells resulted in an accumulation of parasite eggs in the intestines and intestinal haemorrhage, thus preventing the eggs from being excreted. Slightly different effector functions of AAMs come into play in GI helminth infections. Large numbers of AAMs were shown to accumulate in $N$. brasiliensis infection in the gut, characterised by expression of arginase-1, RELM- $\alpha$ and Ym-1, in an IL-4- and IL-13-dependent manner [143]. Macrophage depletion resulted in impaired worm expulsion from the small intestine and prevented smooth muscle hypercontractility.

RELM- $\alpha$ in particular has a clear immunomodulatory role during infection. RELM- $\alpha$ was shown to be essential in regulating lung inflammation, granuloma size and fibrosis in mice challenged with $S$. mansoni eggs [144]. Additionally, RELM- $\alpha$ deficient mice could not control Th2 cell differentiation or cytokine production. Moreover, Pesce et al. illustrated that challenge of RELM- $\alpha$ deficient mice with S. mansoni eggs resulted in elevated eosinophil levels and IgE titres. In the same study RELM- $\alpha$ deficient mice challenged with $N$. brasiliensis infection produced increased Th2 responses, manifested by elevated lung pathology and expulsion of adult worms. Importantly, addition of exogenous RELM- $\alpha$ reversed the pathological Th2 responses in this infection [145]. This represents RELM- $\alpha$ as a key host-derived molecule induced by helminth infection to allow prolonged parasite survival. These studies point at a host protective role for AAMs in specific tissue dwelling and GI helminth infections.

3.3. Regulatory $T$ Cells. Among the cell types targeted during helminth infections, $\mathrm{CD} 4^{+}$Tregs are particularly implicated in controlling innate and adaptive immunity. Natural $\mathrm{CD} 4^{+}$ Tregs develop in the thymus and express the transcription factor Foxp3, the IL-2 receptor $\alpha$ chain (CD25), CTLA-4, and a range of immunosuppressive proteins including IL-10 and TGF- $\beta$ [146]. Additionally, other adaptive CD $25^{+}$Treg populations exist in the periphery that develop from nonregulatory $\mathrm{T}$ cell subsets, with their expression of IL-10 and TGF- $\beta$ distinguishing them from activated $\mathrm{CD} 4{ }^{+} \mathrm{CD} 25^{+}$ nonregulatory $\mathrm{T}$ cells. Tregs are important in reducing 
pathology in the host via suppression of both Th1 and Th2 responses, thus preventing disease symptoms as demonstrated by evidence of Treg involvement in both Th2-mediated allergies and Th1-mediated autoimmunity (reviewed by Else [147]). In a murine model of schistosomiasis $\mathrm{CD} 4{ }^{+} \mathrm{CD} 25^{+}$ $\mathrm{T}$ cells expressing high quantities of IL-10 were shown to play a significant role in reducing immunopathology, especially in the chronic stage of infection [148]. McKee and Pearce illustrated that in S. mansoni-infected mice $\mathrm{CD} 4^{+} \mathrm{CD} 25^{+} \mathrm{Foxp}^{+}{ }^{+}$cells produced significant levels of IL-10 that were required to prevent DC-derived IL-12, thereby suppressing Th1 responses [149]. In fact, isolated schistosome eggs were demonstrated to be capable of modulating Th2 responses, without the need for the former life cycle stages that develop during infection. Schistosome eggs injected into mice were shown to induce a population of Foxp $3^{+}$ cells that expanded to control the $\mathrm{CD}^{+} \mathrm{T}$ cell response, preventing inflammatory Th1 responses while modulating Th2 responses to prevent Th2-mediated immunopathology [150]. Both natural and adaptive Tregs have been described in filarial-infected persons, with the adaptive Treg population producing high levels of IL-10 [151]. Our group has shown that in $H$. polygyrus infection, Foxp $3^{+}$Tregs are a requirement for limiting immunopathology and represent a potential source of IL-10 [152, 153]. Thus, while Treg depletion did not affect worm burdens, the Th2 response was greatly accelerated and augmented, with high levels of IL-4 and IL-13 being produced. The uncontrolled Th2 response led to increased immunopathology in the intestine, demonstrating that Tregs were essential in regulating this response [153]. Foxp $3^{+}$Tregs were also induced after stimulation with $H$. polygyrus ES products, reducing proliferation of effector cells by activating the TGF- $\beta$ signaling pathway [82] During infection, Tregs may therefore be seen as important effector cells required to prevent or reduce pathology in the host by modulating the ensuing Th2 response, thereby simultaneously allowing establishment of chronic infection.

3.4. B Cells. Host protection as well as regulation by antibodies and B cells is being recognised as an essential component in Th2 responses in helminth infections [154]. In S. mansoni-infected mice, where the dominant isotypes are IgG1 and IgE [154], blockade of B cell production resulted in high levels of the proinflammatory cytokines IFN- $\gamma$ and IL-12 but low levels of the Th2 cytokines IL- 4 and IL-10 in acute infection [155]. Moreover mice deficient in B cells could not downregulate granuloma formation in the chronic stage of infection, and this mechanism was mediated by $\mathrm{Fc} \gamma \mathrm{R}$, indicating a role for antibodies in down modulation of pathology [156]. In fact, antibody isotypes are demonstrated to have an important role in determining the outcome of helminth infection in the host. The cytokines IL-4 and IL13 act on B cells to induce both IgG1 and IgE in mice and IgG4 and IgE in humans. High levels of IgG4 but low levels of IgE are found in the blood of hyporesponsive, asymptomatic persons infected with B. malayi, W. bancrofti, and O. volvulus $[16,157]$. IgG4 correlates with high levels of IL-10 and the presence of adult worms in hyporesponsive persons. In Bancroftian filariasis, high levels of IgG4 [158] but low levels of $\operatorname{IgE}$ [159] were found in $\mathrm{mf}$ positive individuals compared to patients with clinical disease (elephantiasis or tropical pulmonary eosinophilia). IgE is known to activate degranulation of mast cells (MCs), basophils and eosinophils and induce antibody-dependent cell-mediated cytoxicity (ADCC) $[154,160]$. IgG1 in mice and IgG4 in humans compete with IgE for binding sites and therefore may inhibit such processes. In fact, IgG4 has downstream suppressive effects, such as inhibiting complement activation [161]. Thus, inhibitory IgG4 may prevent immunopathological responses in helminth asymptomatically infected individuals and can simultaneously provide an indication of the clinical outcome in infected persons.

Regulatory B cells have been first described in autoimmune diseases, where the main mediator of suppression is IL-10 [154]. Helminth infections can also induce specific B cell phenotypes with regulatory properties as shown in infection with $S$. mansoni and $H$. polygyrus [162]. In S. mansoni infection, a particular subset of $\mathrm{B}$ cells has been described that are CD1d $\mathrm{d}^{\text {high }}$ and express high levels of IL-10 (defined as CD19 IL$10^{+} \mathrm{CD} 1 \mathrm{~d}^{\text {high }} \mathrm{CD}^{+} \mathrm{CD} 21^{\text {high }} \mathrm{CD} 23^{+} \mathrm{IgD}^{+} \mathrm{IgM}^{\text {high }}$ cells). Transfer of these cells into OVA-sensitized mice reduced OVAinduced allergic airway inflammation via induction of Foxp $3^{+}$Tregs; the effect was TGF- $\beta$ independent as showed in anti-TGF- $\beta$ mAb treatment experiments [163]. Furthermore, another group demonstrated that transfer of IL-10producing $B$ cells from IL-4 deficient mice infected with $S$. mansoni provided complete resistance to experimentally induced anaphylaxis when applied to naïve mice. Thus, absence of IL-4 was essential to prevent exacerbation of this allergic response [73]. In another study, the same group proved that the protective response of $S$. mansoni infection was entirely dependent on $\mathrm{B}$ cells as depletion of $\mathrm{IgM}^{+}$ $\mathrm{B}$ cells resulted in mice becoming completely susceptible to anaphylaxis [74]. Interestingly, adoptive transfer of a population of $\mathrm{CD} 19^{+} \mathrm{CD} 23^{\text {high }} \mathrm{B}$ cells from $H$. polygyrusinfected mice could reduce the effects of allergic airway inflammation of OVA-sensitized mice, however, in an IL-10 independent manner. These mesenteric lymph node B cells reduced secretion of IL-5 and infiltration of eosinophils into the airways, suppressing allergen-induced pathology [80]. Thus, B cells from helminth infections exhibit regulatory capacity in unrelated diseases and are of therapeutic interest in allergies, therefore their phenotype and functional aspects should be further investigated.

\section{Immunomodulatory Effects of Helminth-Derived Molecules and Their Role in Modulation of Allergy-Related Diseases}

There are numerous studies examining the effects of different helminth infections (e.g., S. mansoni [73-75], H. polygyrus $[78,81,164], N$. brasiliensis [83], Trichinella spiralis [87], and Litomosoides sigmodontis [88]) on allergy-related diseases in experimental animal models, where helminths show the capacity to suppress abberrant Th2 immune responses. In addition, ES products either from $H$. polygyrus [82] or 


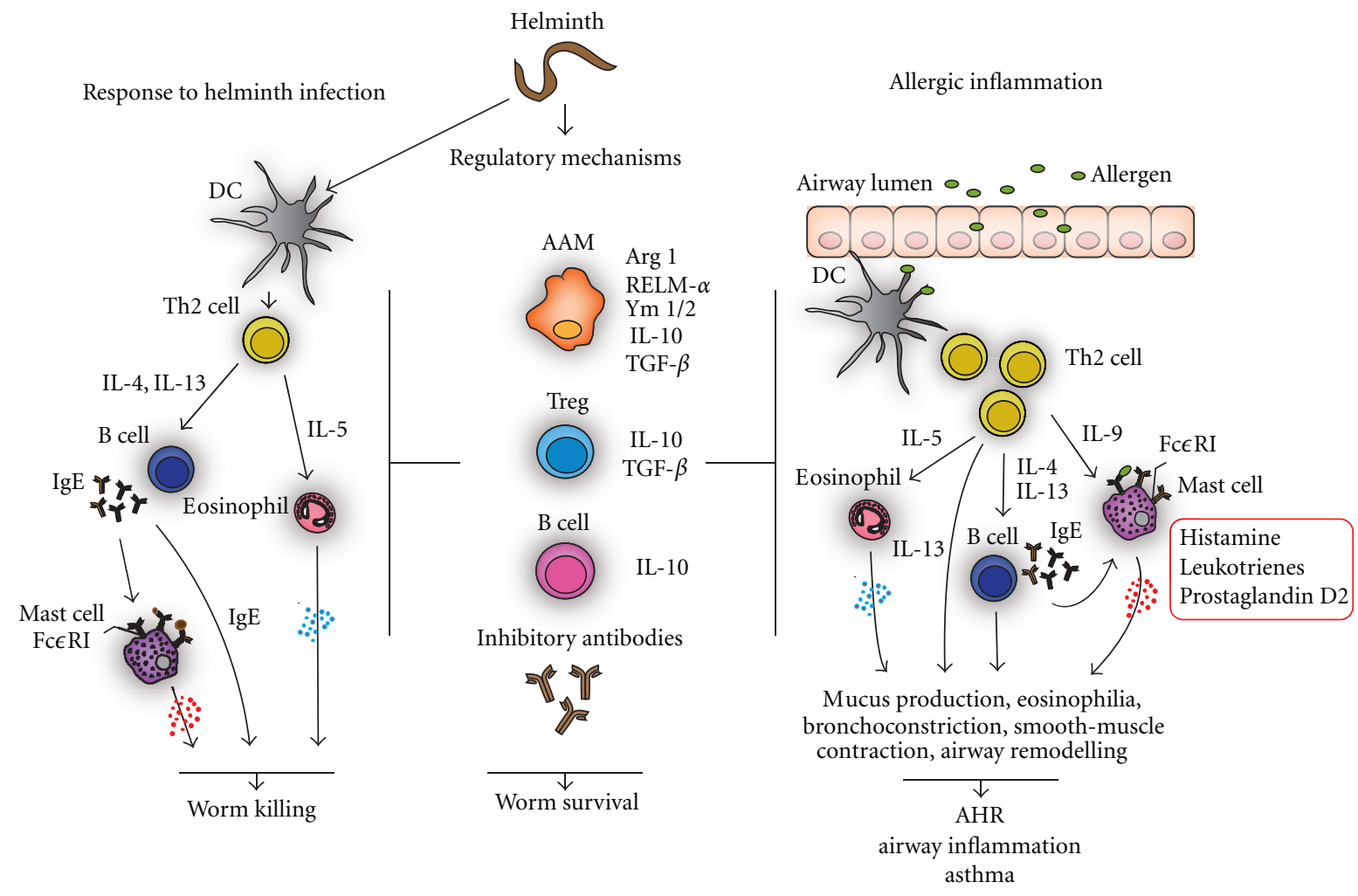

FIGURE 1: Regulatory and effector mechanisms of Th2-type responses. Th2 immune response in helminth infection: helminth infection induces a protective Th2 immune response. Professional antigen presenting cells such as dendritic cells (DCs) process helminth antigens and display them to $\mathrm{CD} 4{ }^{+} \mathrm{T}$ cells that differentiate into polarised T helper 2 cells. Th2 cells produce cytokines such as IL-4, -5 , and -13 that activate and attract macrophages, eosinophils, and other innate immune cells as well as B cells. IL-4 and -13 induce differentiation of antigen-specific $\mathrm{B}$ cells and production of large amounts of antibodies (characteristically IgE). Antibodies opsonise the helminths leading to killing via eosinophils or neutrophils, as well as macrophages by antibody-dependent cellular toxicity (ADCC). IgEs bind to Fce-receptors (FceRI) on mast cells (MCs). Sensitized MCs secrete large amounts of histamine and other mediators and facilitate the attraction and accumulation of further immune cells, which result in larvae killing. Regulatory mechanisms in helminth infection: Helminths induce immunoregulation via modulation of immune cells leading to alternatively activated macrophages (AAMs), regulatory T cells (Treg), and B cells. AAMs in mice express among others arginase-1 (Arg 1), resistin-like molecule- $\alpha$ (RELM- $\alpha$ ), Ym-1, Ym-2, IL-10, and TGF- $\beta$ and contribute to wound healing. Treg produce IL-10 and transforming growth factor- $\beta$ (TGF- $\beta$ ), whereas B cells can elicit regulatory mechanisms via IL10. These cellular changes lead to modified Th2 immune responses and larvae survival as well as blocking of unrelated inflammation such as allergic immune responses. Allergic inflammation: DCs present allergen-derived peptides to T cells. Stimulation of allergen-specific T cells results in differentiation of $\mathrm{CD}^{+}{ }^{+} \mathrm{T}$ cells into Th2 cells that produce Th2 cytokines. IL-4 directs $\mathrm{T}$ cell differentiation towards a Th2-related phenotype. IL-5 regulates the recruitment and differentiation of eosinophils and stimulates them to release mediators. Additionally, IL-4 and -13 induce Ig-class switching to IgE by B cells. IgEs bind to high affinity FceRI on MCs. Sensitized, IL-9-activated, and maturated MCs degranulate and release preformed mediators, including histamine, leukotrienes, and prostaglandins. This allergic inflammatory cascade leads to increased mucus production, eosinophilia, bronchoconstriction, smooth-muscle contraction, and remodelling in the lungs, which result in allergic-airway hyperreactivity (AHR), airway inflammation or asthma. The allergic inflammation may be suppressed by a spill-over effect of immunomodulatory mechanisms of helminth infections.

$N$. brasiliensis [84] were described to have similar beneficial immunoregulatory effects. Furthermore, helminths act through various cell types and can interfere with allergy symptoms in animal models via distinct mechanisms including Tregs $[79,82,88]$, B cells $[73,80,163]$, and induction of regulatory cytokines like IL-10 [78, 81, 83, 87] or TGF$\beta[87,88,163]$, as discussed in the previous section and reviewed in Table 2 .

These and other studies led to the discovery of specific immunomodulatory helminth-derived molecules and products that induce a microenvironment beneficial to the parasite, while at the same time preventing immune-related pathology associated with vigorous Th2 responses (Figure 1). However, as mentioned earlier, persistence of the parasite is not obligatory to reduce allergic symptoms in later life [63]. Moreover, these functionally and structurally diverse molecules are expressed throughout the parasite life cycle and interact directly with host cells. A summary of helminthderived immunomodulatory molecules and products is given in Table 1. We focus here on molecules that are relevant for 
human disease, established animal models of host-parasite interactions, and defined molecules that downregulate unrelated Th2 inflammation.

4.1. Homologues of Mammalian Cytokines and Chemokines. The existence of parasite-derived homologues of host mammalian anti-inflammatory cytokines reveals an apparent evolutionary struggle between the parasite and the host, whereby the parasite has evolved mechanisms to establish chronic infection. For example, two TGF- $\beta$ homologues found in Brugia species, Bm-tgh-1 and Bm-tgh-2, have been well characterised, the second of which is thought to have an immunomodulatory role. TGH-2 is secreted by adult worms and in its recombinant form was shown to bind the human TGF- $\beta$ receptor, thus potentially influencing Treg development $[43,165]$. S. mansoni male worms express a member of the TGF- $\beta$ receptor family known as SmRK-1 [166] for which mammalian TGF- $\beta$ may be a ligand involved in worm development [167]. H. polygyrus ES contains remarkable TGF- $\beta$-like activity, inducing Foxp3 expression in naïve $\mathrm{T}$ cells and modulating immune functions, thereby maintaining worm burdens to induce chronic infection [82].

The beneficial role of homologues of mammalian chemokines such as macrophage migration inhibitory factor (MIF) is less apparent. MIF homologues have been described in multiple helminth species (reviewed elsewhere $[168,169])$. Mammalian MIF has numerous functions, in particular as a proinflammatory cytokine [169]. Helminth MIF has direct chemotactic effects on human monocytes but appears to be associated with anti-inflammatory, modified Th2-type responses [170]. In a murine model of asthma, a recombinant MIF-like protein from $A$. simplex (As-MIF) was described to have a protective effect and to suppress the Th2-type response, reduce production of IL-4, -5 and -13 in the bronchoalveolar lavage fluid (BAL), inhibit eosinophilia, goblet cell hyperplasia, and ameliorate lung hyperreactivity. The effect of $A s$-MIF was possibly mediated by IL-10 and TGF- $\beta$ production in the BAL as well as via Treg induction in the lungs of As-MIF-treated animals when compared to asthmatic controls [66].

Another helminth-derived molecule with structural similarities to mammalian chemokines is Ancylostoma-secreted protein-2 (Na-ASP-2) secreted by the infective larvae of Necator americanus hookworm. Recombinant Na-ASP-2 was shown to recruit high numbers of neutrophils when injected into an air pouch (a sterile inflammatory setting) in mice. The influx of neutrophils was suggested to create permeability in host vessels, thus facilitating larval migration [29]. Hence, cytokine homologues seem to be exploited by the parasite for efficient immune evasion; however more work is needed to assess which of those molecules participate in suppression of unrelated inflammation.

4.2. Protease Inhibitors. The cystatins and serpins are the best-characterised protease inhibitors of helminths that have immunomodulatory potential. Mammalian cysteine proteases are essential for efficient processing and presentation of antigen on MHC class II to induce an appropriate adaptive
T cell response. Mammalian cystatins play a vital role in regulating these pathways; however, helminth cystatins from Acanthocheilonema viteae, B. malayi, N. brasiliensis, and $O$. volvulus have been shown to interfere with this process to dampen antigen-dependent immune reactions (reviewed by Klotz et al. [171]). Bm-CPI-2, a cystatin from B. malayi, was illustrated to interfere with antigen processing, which led to a reduced number of epitopes presented to $\mathrm{T}$ cells in vitro [41]. Studies from our own group have demonstrated that onchocystatin (rOv17) from O. Volvulus reduced antigen-driven proliferation of peripheral blood mononuclear cells in a monocyte-dependent manner [45]. Recombinant AvCystatin (rAv17) from A. viteae has potent immunomodulatory roles illustrated by its ability to reduce antigen-specific and unspecific T cell responses [34]. AvCystatin is recognised by macrophages and upon uptake induces phosphorylation of the mitogen-activated protein kinase signaling pathways ERK1/2 and p38 in macrophages. This led to tyrosine kinase-dependent IL-10 production in macrophages $[34,35]$. Furthermore, we could show in an OVAinduced airway hyperreactivity mouse model that AvCystatin-treated asthmatic mice exhibited amelioration of the disease. AvCystatin administered intraperitoneally (i.p.) during the sensitization phase as well as before challenge with OVA, suppressed recruitment of eosinophils into the lungs, OVAspecific and total IgE levels, and reduced allergen-specific IL4 production. IL-10 is a key element in AvCystatin-induced immunomodulation, as blocking of IL-10 with an antiIL-10R mAb reversed the beneficial effect on cell recruitment and production of IgE [71]. Moreover, depletion of macrophages with clodronate liposomes before airway allergen challenge diminished the antiallergic effect of AvCystatin [71].

The rodent filarial species L. sigmodontis secretes a cystatin at various stages of the life cycle, which after injection via microosmotic pumps into the peritoneal cavity of L. sigmodontis-infected mice greatly decreased nitric oxide production and proliferation of antigen-specific spleen cells [44].

Similarly, recombinant cystatin from the ES product of the GI nematode $N$. brasiliensis (named nippocystatin, NbCys) was shown to inhibit cathepsins $\mathrm{L}$ and $\mathrm{B}$, and suppressed antigen processing by APCs [172]. Furthermore, OVA-sensitized and NbCys-treated mice showed decreased OVA-specific spleen cell proliferation, reduced OVA-specific IgE levels and cytokine production due to inhibition of cathepsin B and L-dependent antigen processing [70].

Similar to cystatins, serpins (serine protease inhibitors) have important roles in mammalian biological processes including regulation of complement activation, inflammatory pathways, and cell interactions. $B m-S P N-2$ is a serpin expressed by $B$. malayi microfilariae, which could inhibit proteases of human neutrophils, thereby interfering with and potentially circumventing the most abundant leukocyte to encounter $\mathrm{mf}$ in the bloodstream [173]. However, another study by Stanley and Stein contests the enzymatic activity of Bm-SPN-2 [174]. Thus, further studies should clarify the role of serpins as immunomodulatory molecules. Taken together, protease inhibitors such as cystatins are a class of 
molecules found in numerous helminths that have important immunomodulatory functions.

4.3. ES-62. A secreted $62 \mathrm{kDa}$ glycoprotein from A. viteae known as ES-62 is one of the best-characterised helminth immunomodulators. ES-62 has been shown to exhibit a plethora of well-documented anti-inflammatory properties [175] and contains phosphorylcholine moieties, which are largely responsible for immunomodulation (reviewed by Harnett et al. [176]). OVA-specific $\mathrm{CD}^{+} \mathrm{T}$ cells exhibited lower levels of proliferation and IL-2 production after challenge with ES-62, as well as inhibition of IL-4 and IL13 [36]. It was also shown that ES-62 acts on macrophages to inhibit production of IL-12 if the cells were subsequently exposed to LPS and IFN- $\gamma$ [37, 38]. ES-62 could also be shown to act on bone-marrow-derived precursors of DCs to inhibit a proinflammatory response induced by LPS [39] and $\mathrm{B}$ cells by modulating $\mathrm{T}$ and $\mathrm{B}$ cell interactions [177]. ES-62 is also active against FceRI-mediated MC responses in vitro. It directly inhibited FceRI-induced release of allergy mediators from human MCs by selectively blocking key signal transduction events. ES-62 also interfered with MCs in vivo in a mouse model of immediate-type hypersensitivity to oxazolone, thereby diminishing ear swelling and MC-dependent hypersensitivity, as well as ex vivo MC degranulation in mice that were previously injected with the molecule. Moreover, ES-62 ameliorated OVA-induced murine airway inflammation, airway hyperresponsiveness, lung pathology, and eosinophilia by suppression of $\mathrm{MC}$ function [72]. Thus, ES-62 is likely to be a key mediator of filarial-induced immunoregulation, and its properties might be used to dampen overwhelming unrelated inflammation in the future.

4.4. Schistosome-Derived Antigens. Schistosome soluble egg antigen (SEA) and ES products released by the egg stage of the parasite contain potent Th2-inducing and immunomodulatory activity. SEA from $S$. mansoni was shown to be an extremely strong inducer of Th2 responses without the need for live infection or the addition of adjuvant [178]. Recently it was shown that omega-1, a hepatotoxic ribonuclease, is one of the key players in this response $[23,24]$. Omega1 is a glycoprotein, which was demonstrated to polarise human monocyte-derived and CD11c $\mathrm{c}^{+}$murine DCs in a direction supporting Th2 responses even in the presence of LPS. In fact, SEA depleted of omega-1 was not able to sufficiently induce a Th2 response in vitro [24]. However, the Th2-suppressive actions of schistosome-derived antigens clearly highlight the ability of this helminth to modulate host immune responses. ES- or omega-1-treated DCs display the typical modulated phenotype that is critical for induction of a Th2 response, including reduced expression of costimulatory molecules and a lowered efficiency in participating in DC-T cell conjugates [23]. In fact, this study demonstrated that omega-1 was shown to alter the morphology of DCs, possibly preventing $\mathrm{T}$ cell activation. IPSE/alpha- 1 is another glycoprotein present in SEA and abundant in ES, which could induce IL-4 production from human basophils in an IgE-dependent but antigen-independent mechanism
[179]. S. mansoni also expresses glycans that have been shown to exhibit immunomodulatory functions. Okano et al. demonstrated that glycan-containing SEA could induce high levels of IL-5, IgE production, and eosinophilia when administered intranasally into mice [178]. The same group was subsequently able to show that $S$. mansoni SEA contained the carbohydrate lacto-N-fucopentaose III (LNFPIII), which induced high levels of IL-4, IL-5, and IL-10 by nasal lymphocytes bypassing the need for an adjuvant [180]. DCs are also targeted by lyso-phosphatidylserine (Lyso-PS) present in SEA, to dampen the Th2 response. Lyso-PS was shown to act on DCs via the TLR2 pathway, endowing them with the ability to induce IL-10-producing Treg cells [19].

Whole SEA, as well as SEA-derived molecules, has been described to interfere with animal models of allergyrelated diseases. Yang et al. used S. japonicum SEA to test its effect in experimentally induced asthma in mice. SEA increased IL-10 production and expression of Foxp3 on $\mathrm{CD} 4{ }^{+} \mathrm{CD} 25^{+} \mathrm{T}$ cells, both with immunosuppressive activity, while at the same time decreasing the expression of Th2 (IL-4 and IL-5) cytokines, suppressed antigen-induced airway inflammation, recruitment of inflammatory cells into the lungs, and development of asthma [76]. S. mansoni egg-secreted chemokine-binding protein (smCKBP) was reported to significantly diminish ear swelling of haptensensitized mice in a contact hypersensitivity model. Isolation of the inflammatory infiltrate from hapten-treated ears of smCKBP-treated mice showed reduction of neutrophilia when compared to cells isolated from the ears of control animals. Smith et al. showed that smCKBP has specific in vivo activity, suppressing immediate or local inflammation [27]. Additionally, three S. mansoni antigens Sm22.6 (soluble protein associated with the $S$. mansoni tegument), PIII (a multivalent antigen of S. mansoni adult worms), and Sm29 (a membrane bound glycoprotein on the S. mansoni adult worm tegument) were evaluated in the OVA-induced airway inflammation mouse model. All three antigens showed a beneficial immunomodulatory effect in this allergy model characterised by suppression of airway inflammation, reduced eosinophilia in the lungs, decreased OVA-specific IgE levels, and lower Th2-specific cytokine production in BAL when compared to asthmatic animals. Sm22.6 significantly induced higher levels of IL-10, while both Sm22.6 and PIII lead to increased expression of $\mathrm{CD} 4^{+} \mathrm{Foxp}^{+} \mathrm{T}$ cells suggesting that Treg cells might be involved in the modulation of this aberrant Th2 inflammation [65].

4.5. Molecules of Ascaris suum. Although Ascaris infections are described to support allergic inflammation (Section 2.3), products from A. suum have also been described to contain immunomodulatory activity, in particular the $200 \mathrm{kDa}$ protein PAS-1. Administration of PAS-1 to mice that had been injected with LPS into sterile air pouches resulted in a significant decrease in neutrophil migration as well as suppressing proinflammatory cytokines IL-6, TNF- $\alpha$, and IL$1 \beta$ [28]. In particular, significant effects of PAS- 1 have been demonstrated in allergy. Itami et al. [67] used a murine model of asthma induced by another A. suum-molecule, APAS-3 that promotes IgE production [181], to test the 
suppressive effect of PAS-1 [182]. In this experimental model of asthma induced by APAS-3, PAS-1-treated mice showed decreased eosinophil migration into the lungs, lower IL-4, IL-5, CCL11 and RANTES production in the BAL, as well as reduced airway hyperreactivity. Moreover, IL-10 production was considerably increased after PAS-1 treatment when compared to APAS-3-immunized controls. Thus, A. suum has allergenic components as well as suppressive products that downregulate allergic responses [67]. More recently, a study from the same group showed suppressive effect of PAS1 also in OVA-induced airway inflammation. In line with previous findings, PAS-1 reduced eosinophilia, decreased production of Th2 associated cytokines in the BAL and OVA-specific IgE and IgG1 levels in serum. Moreover, the effect was observed in IL-12- but not in IL-10- and IFN$\gamma$-deficient animals, thus IL-10 and IFN- $\gamma$ played a role in the immunomodulatory effect of PAS-1 [68]. Furthermore, the authors reported that the immunomodulatory effect of PAS- 1 was mediated by $\mathrm{CD} 4^{+} \mathrm{CD} 25^{+}$and $\mathrm{CD}^{+} \mathrm{T}$ cells as shown by adoptive cell-transfer into OVA-sensitized and challenged mice. Recipients of PAS-1-primed CD $4{ }^{+} \mathrm{CD} 25^{+} \mathrm{T}$ cells had increased levels of IL-10/TGF- $\beta$ whereas mice with transferred PAS-1-primed CD8 ${ }^{+} \mathrm{T}$ cells showed prominent IFN- $\gamma$ production [69]. Those three cytokines were described to play important roles in the suppression of allergic diseases and reported to be strongly induced during successful allergen-specific immunotherapy in humans as reviewed by Holgate and Polosa [183].

\section{Conclusion}

Helminths have had millions of years to evolve regulatory mechanisms that circumvent the mammalian immune response and allow for the longevity characteristically observed during infection. Thus, understanding of this coevolutionary nature is important in order to comprehend the iimmunomodulatory potential of helminth-derived molecules. This will better allow the development of therapeutical targets in symptomatic disease in helminth infections and help to break transmission of infection in endemic countries. Furthermore, the genetic basis underlying differences in responses of different individuals to helminth infections should be examined to develop a full understanding of these parasites, and current studies are beginning to address this. In particular, relevant experimental models for filarial disease are required to study both asymptomatic and pathological responses.

The connection between helminth infections and allergy is of particular interest. The epidemiological data reported in this paper together with experimental studies clearly support the view of the immunomodulatory potential of helminthderived products to interfere with and even prevent aberrant allergic inflammation. These interactions are summarised in Figure 1.

Research should focus on studying the immunomodulatory effects of helminth-derived products on allergy and strive to develop new therapeutic strategies by identifying the mechanisms and pathways utilised by such molecules in mediating their immunomodulatory effects.

\section{Acknowledgments}

The authors thank Dr. Matthew R. Hepworth and Dr. Sebastian Rausch for comments and critical reading of the manuscript. This work was supported by the German Research Council within the GRK 1673, GRK 1121, SFB 650 to S. Hartmann and the Federal Ministry of Education \& Research within the project "Innovative therapies" to S. Hartmann. IMPRS-IDI granted a stipend to N. L. O'Regan. Emilia Daniłowicz-Luebert and Noëlle L. O’Regan contributed equally.

\section{References}

[1] F. D. Finkelman, T. Shea-Donohue, S. C. Morris et al., "Interleukin-4- and interleukin-13-mediated host protection against intestinal nematode parasites," Immunological Reviews, vol. 201, pp. 139-155, 2004.

[2] R. M. Anthony, L. I. Rutitzky, J. F. Urban Jr. et al., "Protective immune mechanisms in helminth infection," Nature Reviews Immunology, vol. 7, no. 12, pp. 975-987, 2007.

[3] R. M. Maizels and M. Yazdanbakhsh, "Immune regulation by helminth parasites: cellular and molecular mechanisms," Nature Reviews Immunology, vol. 3, no. 9, pp. 733-744, 2003.

[4] S. J. Jenkins, D. Ruckerl, P. C. Cook et al., "Local macrophage proliferation, rather than recruitment from the blood, is a signature of TH2 inflammation," Science, vol. 332, no. 6035, pp. 1284-1288, 2011.

[5] J. E. Allen and R. M. Maizels, "Diversity and dialogue in immunity to helminths," Nature Reviews Immunology, vol. 11, no. 6, pp. 375-388, 2011.

[6] H. H. Smits, B. Everts, F. C. Hartgers et al., "Chronic helminth infections protect against allergic diseases by active regulatory processes," Current Allergy and Asthma Reports, vol. 10, no. 1, pp. 3-12, 2010.

[7] S. P. Patel, M. R. Jarvelin, and M. P. Little, "Systematic review of worldwide variations of the prevalence of wheezing symptoms in children," Environmental Health, vol. 7, article 57, 2008.

[8] P. G. Fallon and N. E. Mangan, "Suppression of TH2-type allergic reactions by helminth infection," Nature Reviews Immunology, vol. 7, no. 3, pp. 220-230, 2007.

[9] A. Cooke, "Review series on helminths, immune modulation and the hygiene hypothesis: how might infection modulate the onset of type 1 diabetes?" Immunology, vol. 126, no. 1, pp. 12-17, 2009.

[10] R. M. Maizels, A. Balic, N. Gomez-Escobar et al., "Helminth parasites-masters of regulation," Immunological Reviews, vol. 201, pp. 89-116, 2004.

[11] C. L. King and T. B. Nutman, "Regulation of the immune response in lymphatic filariasis and onchocerciasis," Immunology Today, vol. 12, no. 3, pp. A54-A58, 1991.

[12] E. A. Ottesen, P. F. Weller, and L. Heck, "Specific cellular immune unresponsiveness in human filariasis," Immunology, vol. 33, no. 3, pp. 413-421, 1977.

[13] P. F. Weller, E. A. Ottesen, L. Heck et al., "Endemic filariasis on a Pacific island. I. Clinical, epidemiologic, and parasitologic aspects," American Journal of Tropical Medicine and Hygiene, vol. 31, no. 5, pp. 942-952, 1982.

[14] E. A. Ottesen, "Immunopathology of lymphatic filariasis in man," Springer Seminars in Immunopathology, vol. 2, no. 4, pp. 373-385, 1980. 
[15] E. A. Ottesen and T. B. Nutman, "Tropical pulmonary eosinophilia," Annual Review of Medicine, vol. 43, pp. 417-424, 1992.

[16] N. W. Brattig, "Pathogenesis and host responses in human onchocerciasis: impact of Onchocerca filariae and Wolbachia endobacteria," Microbes and Infection, vol. 6, no. 1, pp. 113128,2004

[17] R. Rigano, B. Buttari, E. Profumo et al., "Echinococcus granulosus antigen B impairs human dendritic cell differentiation and polarizes immature dendritic cell maturation towards a Th2 cell response," Infection and Immunity, vol. 75, no. 4, pp. 1667-1678, 2007.

[18] S. Donnelly, S. M. O'Neill, C. M. Stack et al., "Helminth cysteine proteases inhibit TRIF-dependent activation of macrophages via degradation of TLR3," Journal of Biological Chemistry, vol. 285, no. 5, pp. 3383-3392, 2010.

[19] D. van der Kleij, E. Latz, J. F. Brouwers et al., "A novel host-parasite lipid cross-talk. Schistosomal lyso-phosphatidylserine activates toll-like receptor 2 and affects immune polarization," Journal of Biological Chemistry, vol. 277, no. 50, pp. 48122-48129, 2002.

[20] E. van Riet, B. Everts, K. Retra et al., "Combined TLR2 and TLR4 ligation in the context of bacterial or helminth extracts in human monocyte derived dendritic cells: molecular correlates for Th1/Th2 polarization," BMC Immunology, vol. 10, article 9, 2009.

[21] E. Aksoy, C. S. Zouain, F. Vanhoutte et al., "Double-stranded RNAs from the helminth parasite Schistosoma activate TLR3 in dendritic cells," Journal of Biological Chemistry, vol. 280, no. 1, pp. 277-283, 2005.

[22] F. Vanhoutte, L. Breuilh, J. Fontaine et al., “Toll-like receptor (TLR)2 and TLR3 sensing is required for dendritic cell activation, but dispensable to control Schistosoma mansoni infection and pathology," Microbes and Infection, vol. 9, no. 14-15, pp. 1606-1613, 2007.

[23] S. Steinfelder, J. F. Andersen, J. L. Cannons et al., "The major component in schistosome eggs responsible for conditioning dendritic cells for Th2 polarization is a T2 ribonuclease (omega-1)," Journal of Experimental Medicine, vol. 206, no. 8, pp. 1681-1690, 2009.

[24] B. Everts, G. Perona-Wright, H. H. Smits et al., "Omega-1, a glycoprotein secreted by Schistosoma mansoni eggs, drives Th2 responses," Journal of Experimental Medicine, vol. 206, no. 8, pp. 1673-1680, 2009.

[25] P. Zaccone, O. T. Burton, S. E. Gibbs et al., "The S. mansoni glycoprotein omega-1 induces Foxp3 expression in NOD mouse CD4(+) T cells," European Journal of Immunology, vol. 41, no. 9, pp. 2709-2718, 2011.

[26] G. Schramm, K. Mohrs, M. Wodrich et al., "Cutting edge: IPSE/alpha-1, a glycoprotein from Schistosoma mansoni eggs, induces IgE-dependent, antigen-independent IL-4 production by murine basophils in vivo," Journal of Immunology, vol. 178, no. 10, pp. 6023-6027, 2007.

[27] P. Smith, R. E. Fallon, N. E. Mangan et al., "Schistosoma mansoni secretes a chemokine binding protein with antiinflammatory activity," Journal of Experimental Medicine, vol. 202, no. 10, pp. 1319-1325, 2005.

[28] T. M. Oshiro, M. S. Macedo, and M. F. Macedo-Soares, "Anti-inflammatory activity of PAS-1, a protein component of Ascaris suum," Inflammation Research, vol. 54, no. 1, pp. 17-21, 2005
[29] M. A. Bower, S. L. Constant, and S. Mendez, "Necator americanus the Na-ASP-2 protein secreted by the infective larvae induces neutrophil recruitment in vivo and in vitro," Experimental Parasitology, vol. 118, no. 4, pp. 569-575, 2008.

[30] F. J. Culley, A. Brown, D. M. Conroy, I. Sabroe, D. I. Pritchard, and T. J. Williams, "Eotaxin is specifically cleaved by hookworm metalloproteases preventing its action in vitro and in vivo," Journal of Immunology, vol. 165, no. 11, pp. 6447-6453, 2000.

[31] M. E. Grigg, K. Gounaris, and M. E. Selkirk, "Characterization of a platelet-activating factor acetylhydrolase secreted by the nematode parasite Nippostrongylus brasiliensis," Biochemical Journal, vol. 317, no. 2, pp. 541-547, 1996.

[32] T. H. Tan, S. A. Edgerton, R. Kumari et al., "Macrophage migration inhibitory factor of the parasitic nematode Trichinella spiralis," Biochemical Journal, vol. 357, no. 2, pp. 373-383, 2001.

[33] R. K. Grencis and G. M. Entwistle, "Production of an interferon-gamma homologue by an intestinal nematode: functionally significant or interesting artefact?" Parasitology, vol. 115, supplement, pp. S101-S106, 1997.

[34] S. Hartmann, B. Kyewski, B. Sonnenburg, and R. Lucius, "A filarial cysteine protease inhibitor down-regulates $\mathrm{T}$ cell proliferation and enhances interleukin-10 production," European Journal of Immunology, vol. 27, no. 9, pp. 22532260, 1997.

[35] C. Klotz, T. Ziegler, A. S. Figueiredo et al., "A helminth immunomodulator exploits host signaling events to regulate cytokine production in macrophages," PLoS Pathogens, vol. 7, no. 1, article e1001248, 2011.

[36] F. A. Marshall, A. M. Grierson, P. Garside et al., "ES-62, an immunomodulator secreted by filarial nematodes, suppresses clonal expansion and modifies effector function of heterologous antigen-specific T cells in vivo," Journal of Immunology, vol. 175, no. 9, pp. 5817-5826, 2005.

[37] H. S. Goodridge, E. H. Wilson, W. Harnett et al., "Modulation of macrophage cytokine production by ES-62, a secreted product of the filarial nematode Acanthocheilonema viteae," Journal of Immunology, vol. 167, no. 2, pp. 940-945, 2001.

[38] H. S. Goodridge, F. A. Marshall, K. J. Else et al., "Immunomodulation via novel use of TLR4 by the filarial nematode phosphorylcholine-containing secreted product, ES-62," Journal of Immunology, vol. 174, no. 1, pp. 284-293, 2005.

[39] H. S. Goodridge, F. A. Marshall, E. H. Wilson et al., "In vivo exposure of murine dendritic cell and macrophage bone marrow progenitors to the phosphorylcholine-containing filarial nematode glycoprotein ES-62 polarizes their differentiation to an anti-inflammatory phenotype," Immunology, vol. 113, no. 4, pp. 491-498, 2004.

[40] N. Gomez-Escobar, C. Bennett, L. Prieto-Lafuente et al., "Heterologous expression of the filarial nematode alt gene products reveals their potential to inhibit immune function," BMC Biology, vol. 3, article 8, 2005.

[41] B. Manoury, W. F. Gregory, R. M. Maizels et al., “Bm-CPI2, a cystatin homolog secreted by the filarial parasite Brugia malayi, inhibits class II MHC-restricted antigen processing," Current Biology, vol. 11, no. 6, pp. 447-451, 2001.

[42] J. Murray, B. Manoury, A. Balic et al., "Bm-CPI-2, a cystatin from Brugia malayi nematode parasites, differs from Caenorhabditis elegans cystatins in a specific site mediating inhibition of the antigen-processing enzyme AEP," Molecular and Biochemical Parasitology, vol. 139, no. 2, pp. 197-203, 2005. 
[43] N. Gomez-Escobar, W. F. Gregory, and R. M. Maizels, "Identification of tgh-2, a filarial nematode homolog of Caenorhabditis elegans daf- 7 and human transforming growth factor $\beta$, expressed in microfilarial and adult stages of Brugia malayi," Infection and Immunity, vol. 68 , no. 11, pp. 64026410, 2000.

[44] A. W. Pfaff, H. Schulz-Key, P. T. Soboslay et al., "Litomosoides sigmodontis cystatin acts as an immunomodulator during experimental filariasis," International Journal for Parasitology, vol. 32, no. 2, pp. 171-178, 2002.

[45] A. Schönemeyer, R. Lucius, B. Sonnenburg et al., "Modulation of human $\mathrm{T}$ cell responses and macrophage functions by onchocystatin, a secreted protein of the filarial nematode Onchocerca volvulus," Journal of Immunology, vol. 167, no. 6, pp. 3207-3215, 2001.

[46] S. Lustigman, B. Brotman, T. Huima et al., "Molecular cloning and characterization of onchocystatin, a cysteine proteinase inhibitor of Onchocerca volvulus," Journal of Biological Chemistry, vol. 267, no. 24, pp. 17339-17346, 1992.

[47] S. Babu, S. Q. Bhat, N. P. Kumar et al., "Attenuation of tolllike receptor expression and function in latent tuberculosis by coexistent filarial infection with restoration following antifilarial chemotherapy," PLoS Neglected Tropical Diseases, vol. 3, no. 7, article e489, 2009.

[48] S. Metenou, B. Dembele, S. Konate et al., "Filarial infection suppresses malaria-specific multifunctional Th1 and Th17 responses in malaria and filarial coinfections," Journal of Immunology, vol. 186, no. 8, pp. 4725-4733, 2011.

[49] P. J. Cooper, M. Chico, C. Sandoval et al., "Human infection with Ascaris lumbricoides is associated with suppression of the interleukin-2 response to recombinant cholera toxin B subunit following vaccination with the live oral cholera vaccine CVD 103-HgR," Infection and Immunity, vol. 69, no. 3, pp. 1574-1580, 2001.

[50] D. P. Strachan, "Hay fever, hygiene, and household size," British Medical Journal, vol. 299, no. 6710, pp. 1259-1260, 1989.

[51] M. Yazdanbakhsh, P. G. Kremsner, and R. van Ree, "Allergy, parasites, and the hygiene hypothesis," Science, vol. 296, no. 5567, pp. 490-494, 2002.

[52] C. Flohr, R. J. Quinnell, and J. Britton, "Do helminth parasites protect against atopy and allergic disease?" Clinical and Experimental Allergy, vol. 39, no. 1, pp. 20-32, 2009.

[53] A. H. van den Biggelaar, R. van Ree, L. C. Rodrigues et al., "Decreased atopy in children infected with Schistosoma haematobium: a role for parasite-induced interleukin-10," Lancet, vol. 356, no. 9243, pp. 1723-1727, 2000.

[54] M. I. Araujo, A. A. Lopes, M. Medeiros et al., "Inverse association between skin response to aeroallergens and Schistosoma mansoni infection," International Archives of Allergy and Immunology, vol. 123, no. 2, pp. 145-148, 2000.

[55] M. Medeiros Jr., J. P. Figueiredo, M. C. Almeida et al., "Schistosoma mansoni infection is associated with a reduced course of asthma," Journal of Allergy and Clinical Immunology, vol. 111, no. 5, pp. 947-951, 2003.

[56] P. J. Cooper, M. E. Chico, L. C. Rodrigues et al., "Reduced risk of atopy among school-age children infected with geohelminth parasites in a rural area of the tropics," Journal of Allergy and Clinical Immunology, vol. 111, no. 5, pp. 9951000, 2003.

[57] S. Scrivener, H. Yemaneberhan, M. Zebenigus et al., "Independent effects of intestinal parasite infection and domestic allergen exposure on risk of wheeze in Ethiopia: s nested casecontrol study," Lancet, vol. 358, no. 9292, pp. 1493-1499, 2001.
[58] O. A. Nyan, G. E. Walraven, W. A. Banya et al., "Atopy, intestinal helminth infection and total serum IgE in rural and urban adult Gambian communities," Clinical and Experimental Allergy, vol. 31, no. 11, pp. 1672-1678, 2001.

[59] A. H. van den Biggelaar, L. C. Rodrigues, R. van Ree et al., "Long-term treatment of intestinal helminths increases mite skin-test reactivity in Gabonese schoolchildren," Journal of Infectious Diseases, vol. 189, no. 5, pp. 892-900, 2004.

[60] N. R. Lynch, I. Hagel, M. Perez et al., "Effect of anthelmintic treatment on the allergic reactivity of children in a tropical slum," Journal of Allergy and Clinical Immunology, vol. 92, no. 3, pp. 404-411, 1993.

[61] C. Flohr, L. N. Tuyen, R. J. Quinnell et al., "Reduced helminth burden increases allergen skin sensitization but not clinical allergy: a randomized, double-blind, placebo-controlled trial in Vietnam," Clinical and Experimental Allergy, vol. 40, no. 1, pp. 131-142, 2010.

[62] P. Endara, M. Vaca, M. E. Chico et al., "Long-term periodic anthelmintic treatments are associated with increased allergen skin reactivity," Clinical and Experimental Allergy, vol. 40, no. 11, pp. 1669-1677, 2010.

[63] L. C. Rodrigues, P. J. Newcombe, S. S. Cunha et al., "Early infection with Trichuris trichiura and allergen skin test reactivity in later childhood," Clinical and Experimental Allergy, vol. 38, no. 11, pp. 1769-1777, 2008.

[64] S. L. Huang, P. F. Tsai, and Y. F. Yeh, "Negative association of Enterobius infestation with asthma and rhinitis in primary school children in Taipei," Clinical and Experimental Allergy, vol. 32, no. 7, pp. 1029-1032, 2002.

[65] L. S. Cardoso, S. C. Oliveira, A. M. Goes et al., "Schistosoma mansoni antigens modulate the allergic response in a murine model of ovalbumin-induced airway inflammation," Clinical and Experimental Immunology, vol. 160, no. 2, pp. 266-274, 2010.

[66] S. K. Park, M. K. Cho, H. K. Park et al., "Macrophage migration inhibitory factor homologs of Anisakis simplex suppress Th2 response in allergic airway inflammation model via CD4 +CD25+Foxp3+ T cell recruitment," Journal of Immunology, vol. 182, no. 11, pp. 6907-6914, 2009.

[67] D. M. Itami, T. M. Oshiro, C. A. Araujo et al., "Modulation of murine experimental asthma by Ascaris suum components," Clinical and Experimental Allergy, vol. 35, no. 7, pp. 873-879, 2005.

[68] C. A. Araujo, A. Perini, M. A. Martins et al., "PAS-1, a protein from Ascaris suum, modulates allergic inflammation via IL10 and IFN- $\gamma$, but not IL-12," Cytokine, vol. 44, no. 3, pp. 335-341, 2008.

[69] C. A. de Araujo, A. Perini, M. A. Martins et al., "PAS-1, an Ascaris suum protein, modulates allergic airway inflammation via CD8+ $\gamma \delta$ TCR+ and CD4+ CD25+ FoxP3+ T Cells," Scandinavian Journal of Immunology, vol. 72, no. 6, pp. 491$503,2010$.

[70] T. Dainichi, Y. Maekawa, K. Ishii et al., "Nippocystatin, a cysteine protease inhibitor from Nippostrongylus brasiliensis, inhibits antigen processing and modulates antigen-specific immune response," Infection and Immunity, vol. 69, no. 12, pp. 7380-7386, 2001.

[71] C. Schnoeller, S. Rausch, S. Pillai et al., "A helminth immunomodulator reduces allergic and inflammatory responses by induction of IL-10-producing macrophages," Journal of Immunology, vol. 180, no. 6, pp. 4265-4272, 2008.

[72] A. J. Melendez, M. M. Harnett, P. N. Pushparaj et al., "Inhibition of FceRI-mediated mast cell responses by ES-62, a product of parasitic filarial nematodes," Nature Medicine, vol. 13, no. 11, pp. 1375-1381, 2007. 
[73] N. E. Mangan, R. E. Fallon, P. Smith et al., "Helminth infection protects mice from anaphylaxis via IL-10-producing B cells," Journal of Immunology, vol. 173, no. 10, pp. 6346-6356, 2004.

[74] N. E. Mangan, N. Van Rooijen, A. N. McKenzie et al., "Helminth-modified pulmonary immune response protects mice from allergen-induced airway hyperresponsiveness," Journal of Immunology, vol. 176, no. 1, pp. 138-147, 2006.

[75] L. G. Pacifico, F. A. Marinho, C. T. Fonseca et al., "Schistosoma mansoni antigens modulate experimental allergic asthma in a murine model: a major role for CD4+ CD25+ Foxp3 + T cells independent of interleukin-10," Infection and Immunity, vol. 77, no. 1, pp. 98-107, 2009.

[76] J. Yang, J. Zhao, Y. Yang et al., "Schistosoma japonicum egg antigens stimulate CD4+ CD25 + T cells and modulate airway inflammation in a murine model of asthma," Immunology, vol. 120, no. 1, pp. 8-18, 2007.

[77] C. Lima, A. Perini, M. L. Garcia et al., "Eosinophilic inflammation and airway hyper-responsiveness are profoundly inhibited by a helminth (Ascaris suum) extract in a murine model of asthma," Clinical and Experimental Allergy, vol. 32, no. 11, pp. 1659-1666, 2002.

[78] K. Kitagaki, T. R. Businga, D. Racila et al., "Intestinal helminths protect in a murine model of asthma," Journal of Immunology, vol. 177, no. 3, pp. 1628-1635, 2006.

[79] M. S. Wilson, M. D. Taylor, A. Balic et al., "Suppression of allergic airway inflammation by helminth-induced regulatory T cells," Journal of Experimental Medicine, vol. 202, no. 9, pp. 1199-1212, 2005.

[80] M. S. Wilson, M. D. Taylor, M. T. O’Gorman et al., "Helminth-induced CD19+CD23hi B cells modulate experimental allergic and autoimmune inflammation," European Journal of Immunology, vol. 40, no. 6, pp. 1682-1696, 2010.

[81] M. E. Bashir, P. Andersen, I. J. Fuss et al., "An enteric helminth infection protects against an allergic response to dietary antigen," Journal of Immunology, vol. 169, no. 6, pp. 3284-3292, 2002.

[82] J. R. Grainger, K. A. Smith, J. P. Hewitson et al., "Helminth secretions induce de novo $\mathrm{T}$ cell Foxp3 expression and regulatory function through the TGF- $\beta$ pathway," Journal of Experimental Medicine, vol. 207, no. 11, pp. 2331-2341, 2010.

[83] G. Wohlleben, C. Trujillo, J. Muller et al., "Helminth infection modulates the development of allergen-induced airway inflammation," International Immunology, vol. 16, no. 4, pp. 585-596, 2004.

[84] C. M. Trujillo-Vargas, M. Werner-Klein, G. Wohlleben et al., "Helminth-derived products inhibit the development of allergic responses in mice," American Journal of Respiratory and Critical Care Medicine, vol. 175, no. 4, pp. 336-344, 2007.

[85] C. C. Wang, T. J. Nolan, G. A. Schad, and D. Abraham, "Infection of mice with the helminth Strongyloides stercoralis suppresses pulmonary allergic responses to ovalbumin," Clinical and Experimental Allergy, vol. 31, no. 3, pp. 495-503, 2001.

[86] D. Negrão-Corrêa, M. R. Silveira, C. M. Borges et al., "Changes in pulmonary function and parasite burden in rats infected with Strongyloides venezuelensis concomitant with induction of allergic airway inflammation," Infection and Immunity, vol. 71, no. 5, pp. 2607-2614, 2003.

[87] H. K. Park, M. K. Cho, S. H. Choi et al., "Trichinella spiralis: infection reduces airway allergic inflammation in mice," Experimental Parasitology, vol. 127, no. 2, pp. 539-544, 2011.

[88] A. M. Dittrich, A. Erbacher, S. Specht et al., "Helminth infection with Litomosoides sigmodontis induces regulatory $\mathrm{T}$ cells and inhibits allergic sensitization, airway inflammation, and hyperreactivity in a murine asthma model," Journal of Immunology, vol. 180, no. 3, pp. 1792-1799, 2008.

[89] U. Herz, A. Braun, R. Ruckert et al., "Various immunological phenotypes are associated with increased airway responsiveness," Clinical and Experimental Allergy, vol. 28, no. 5, pp. 625-634, 1998.

[90] A. M. Dittrich, M. Krokowski, H. A. Meyer et al., "Lipocalin2 protects against airway inflammation and hyperresponsiveness in a murine model of allergic airway disease," Clinical and Experimental Allergy, vol. 40, no. 11, pp. 1689-1700, 2010.

[91] M. J. Makela, A. Kanehiro, L. Borish et al., "IL-10 is necessary for the expression of airway hyperresponsiveness but not pulmonary inflammation after allergic sensitization," Proceedings of the National Academy of Sciences of the United States of America, vol. 97, no. 11, pp. 6007-6012, 2000.

[92] E. Hamelmann, K. Tadeda, A. Oshiba et al., "Role of IgE in the development of allergic airway inflammation and airway hyperresponsiveness-a murine model," Allergy, vol. 54, no. 4, pp. 297-305, 1999.

[93] E. Hamelmann, U. Wahn, and E. W. Gelfand, "Role of the Th2 cytokines in the development of allergen-induced airway inflammation and hyperresponsiveness," International Archives of Allergy and Immunology, vol. 118, no. 2-4, pp. 9094, 1999.

[94] A. Heinzmann, X. Q. Mao, M. Akaiwa et al., "Genetic variants of IL-13 signalling and human asthma and atopy," Human Molecular Genetics, vol. 9, no. 4, pp. 549-559, 2000.

[95] K. Arima, R. Umeshita-Suyama, Y. Sakata et al., "Upregulation of IL-13 concentration in vivo by the IL13 variant associated with bronchial asthma," Journal of Allergy and Clinical Immunology, vol. 109, no. 6, pp. 980-987, 2002.

[96] P. S. Gao, N. M. Heller, W. Walker et al., "Variation in dinucleotide (GT) repeat sequence in the first exon of the STAT6 gene is associated with atopic asthma and differentially regulates the promoter activity in vitro," Journal of Medical Genetics, vol. 41, no. 7, pp. 535-539, 2004.

[97] K. Tamura, H. Arakawa, M. Suzuki et al., "Novel dinucleotide repeat polymorphism in the first exon of the STAT- 6 gene is associated with allergic diseases," Clinical and Experimental Allergy, vol. 31, no. 10, pp. 1509-1514, 2001.

[98] C. V. Scirica and J. C. Celedon, "Genetics of asthma potential implications for reducing asthma disparities," Chest, vol. 132, supplement 5, pp. 770S-781S, 2007.

[99] K. C. Barnes, A. V. Grant, N. N. Hansel et al., "African Americans with asthma: genetic insights," Proceedings of the American Thoracic Society, vol. 4, no. 1, pp. 58-68, 2007.

[100] J. R. Joubert, D. J. van Schalkwyk, and K. J. Turner, “Ascaris lumbricoides and the human immunogenetic response. Enhanced IgE-mediated reactivity to common inhaled allergens," South African Medical Journal, vol. 57, no. 11, pp. 409412, 1980.

[101] S. Dold, J. Heinrich, H. E. Wichmann et al., “Ascaris-specific $\mathrm{IgE}$ and allergic sensitization in a cohort of school children in the former East Germany," Journal of Allergy and Clinical Immunology, vol. 102, no. 3, pp. 414-420, 1998.

[102] L. J. Palmer, J. C. Celedon, S. T. Weiss et al., "Ascaris lumbricoides infection is associated with increased risk of childhood asthma and atopy in rural China," American Journal of Respiratory and Critical Care Medicine, vol. 165, no. 11, pp. 1489-1493, 2002. 
[103] J. Leonardi-Bee, D. Pritchard, and J. Britton, "Asthma and current intestinal parasite infection: systematic review and meta-analysis," American Journal of Respiratory and Critical Care Medicine, vol. 174, no. 5, pp. 514-523, 2006.

[104] H. Takeuchi, K. Zaman, J. Takahashi et al., "High titre of antiAscaris immunoglobulin E associated with bronchial asthma symptoms in 5-year-old rural Bangladeshi children," Clinical and Experimental Allergy, vol. 38, no. 2, pp. 276-282, 2008.

[105] I. Hagel, M. Cabrera, M. A. Hurtado et al., "Infection by Ascaris lumbricoides and bronchial hyper reactivity: an outstanding association in Venezuelan school children from endemic areas," Acta Tropica, vol. 103, no. 3, pp. 231-241, 2007.

[106] N. M. Alcantara-Neves, S. J. Badaro, M. C. dos Santos et al., "The presence of serum anti-Ascaris lumbricoides IgE antibodies and of Trichuris trichiura infection are risk factors for wheezing and/or atopy in preschool-aged Brazilian children," Respiratory Research, vol. 11, p. 114, 2010.

[107] C. S. Enobe, C. A. Araujo, A. Perini et al., "Early stages of Ascaris suum induce airway inflammation and hyperreactivity in a mouse model," Parasite Immunology, vol. 28, no. 9, pp. 453-461, 2006.

[108] N. Acevedo and L. Caraballo, "IgE cross-reactivity between Ascaris lumbricoides and mite allergens: possible influences on allergic sensitization and asthma," Parasite Immunology, vol. 33, no. 6, pp. 309-321, 2011.

[109] G. Reese, R. Ayuso, and S. B. Lehrer, "Tropomyosin: an invertebrate pan-allergen," International Archives of Allergy and Immunology, vol. 119, no. 4, pp. 247-258, 1999.

[110] N. Acevedo, J. Sanchez, A. Erler et al., "IgE cross-reactivity between Ascaris and domestic mite allergens: the role of tropomyosin and the nematode polyprotein ABA-1," Allergy, vol. 64, no. 11, pp. 1635-1643, 2009.

[111] N. Acevedo, A. Erler, P. Briza et al., "Allergenicity of Ascaris lumbricoides tropomyosin and IgE sensitization among asthmatic patients in a tropical environment," International Archives of Allergy and Immunology, vol. 154, no. 3, pp. 195206, 2010.

[112] A. Gonzalez-Quintela, F. Gude, J. Campos et al., "Toxocara infection seroprevalence and its relationship with atopic features in a general adult population," International Archives of Allergy and Immunology, vol. 139, no. 4, pp. 317-324, 2006.

[113] O. Barbuzza, F. Guarneri, G. Galtieri et al., "Protein contact dermatitis and allergic asthma caused by Anisakis simplex," Contact Dermatitis, vol. 60, no. 4, pp. 239-240, 2009.

[114] A. Daschner, C. Cuellar, and A. Valls, "Towards a differential definition of atopy: Anisakis simplex and the relationship between parasites and arthropods in respiratory allergy," Parasite Immunology, vol. 30, no. 8, pp. 417-424, 2008.

[115] A. Daschner, C. De Frutos, A. Valls et al., "Anisakis simplex sensitization-associated urticaria: short-lived immediate type or prolonged acute urticaria," Archives of Dermatological Research, vol. 302, no. 8, pp. 625-629, 2010.

[116] E. Sartono, Y. C. Kruize, A. Kurniawan et al., "Elevated cellular immune responses and interferon- $\gamma$ release after longterm diethylcarbamazine treatment of patients with human lymphatic filariasis," Journal of Infectious Diseases, vol. 171, no. 6, pp. 1683-1687, 1995.

[117] A. A. Da'dara and D. A. Harn, "Elimination of helminth infection restores HIV-1C vaccine-specific $\mathrm{T}$ cell responses independent of helminth-induced IL-10," Vaccine, vol. 28, no. 5, pp. 1310-1317, 2010.
[118] D. Elias, D. Wolday, H. Akuffo et al., "Effect of deworming on human $\mathrm{T}$ cell responses to mycobacterial antigens in helminth-exposed individuals before and after bacille Calmette-Guerin (BCG) vaccination," Clinical and Experimental Immunology, vol. 123, no. 2, pp. 219-225, 2001.

[119] A. Balic, Y. Harcus, M. J. Holland et al., "Selective maturation of dendritic cells by Nippostrongylus brasiliensis-secreted proteins drives Th2 immune responses," European Journal of Immunology, vol. 34, no. 11, pp. 3047-3059, 2004.

[120] M. Segura, Z. Su, C. Piccirillo et al., "Impairment of dendritic cell function by excretory-secretory products: a potential mechanism for nematode-induced immunosuppression," European Journal of Immunology, vol. 37, no. 7, pp. 18871904, 2007.

[121] R. T. Semnani, H. Sabzevari, R. Iyer et al., "Filarial antigens impair the function of human dendritic cells during differentiation," Infection and Immunity, vol. 69, no. 9, pp. 58135822, 2001.

[122] R. T. Semnani, P. G. Venugopal, C. A. Leifer et al., "Inhibition of TLR3 and TLR4 function and expression in human dendritic cells by helminth parasites," Blood, vol. 112, no. 4, pp. 1290-1298, 2008.

[123] C. A. Terrazas, L. I. Terrazas, and L. Gomez-Garcia, "Modulation of dendritic cell responses by parasites: a common strategy to survive," Journal of Biomedicine \& Biotechnology, vol. 2010, Article ID 357106, 19 pages, 2010.

[124] L. Carvalho, J. Sun, C. Kane et al., "Review series on helminths, immune modulation and the hygiene hypothesis: mechanisms underlying helminth modulation of dendritic cell function," Immunology, vol. 126, no. 1, pp. 28-34, 2009.

[125] R. T. Semnani, A. Y. Liu, H. Sabzevari et al., "Brugia malayi microfilariae induce cell death in human dendritic cells, inhibit their ability to make IL-12 and IL-10, and reduce their capacity to activate CD4+ T cells," Journal of Immunology, vol. 171, no. 4, pp. 1950-1960, 2003.

[126] J. C. Massacand, R. C. Stettler, R. Meier et al., "Helminth products bypass the need for TSLP in Th2 immune responses by directly modulating dendritic cell function," Proceedings of the National Academy of Sciences of the United States of America, vol. 106, no. 33, pp. 13968-13973, 2009.

[127] C. A. Terrazas, L. Gomez-Garcia, and L. I. Terrazas, "Impaired pro-inflammatory cytokine production and increased Th2-biasing ability of dendritic cells exposed to Taenia excreted/secreted antigens: a critical role for carbohydrates but not for STAT6 signaling," International Journal for Parasitology, vol. 40, no. 9, pp. 1051-1062, 2010.

[128] D. J. Dowling, C. M. Noone, P. N. Adams et al., "Ascaris lumbricoides pseudocoelomic body fluid induces a partially activated dendritic cell phenotype with Th2 promoting ability in vivo," International Journal for Parasitology, vol. 41, no. 2, pp. 255-261, 2010.

[129] K. A. Smith, K. Hochweller, G. J. Hammerling et al., "Chronic helminth infection promotes immune regulation in vivo through dominance of CD11cloCD103- dendritic cells," Journal of Immunology, vol. 186, no. 12, pp. 7098-7109, 2011.

[130] A. T. Phythian-Adams, P. C. Cook, R. J. Lundie et al., "CD11c depletion severely disrupts Th2 induction and development in vivo," Journal of Experimental Medicine, vol. 207, no. 10, pp. 2089-2096, 2010.

[131] A. Hoerauf, J. Satoguina, M. Saeftel et al., "Immunomodulation by filarial nematodes," Parasite Immunology, vol. 27, no. 10-11, pp. 417-429, 2005. 
[132] S. Gordon and F. O. Martinez, "Alternative activation of macrophages: mechanism and functions," Immunity, vol. 32, no. 5, pp. 593-604, 2010.

[133] J. L. Reyes and L. I. Terrazas, "The divergent roles of alternatively activated macrophages in helminthic infections," Parasite Immunology, vol. 29, no. 12, pp. 609-619, 2007.

[134] J. T. Pesce, T. R. Ramalingam, M. M. Mentink-Kane et al., "Arginase-1-expressing macrophages suppress Th2 cytokinedriven inflammation and fibrosis," PLoS Pathogens, vol. 5, no. 4, Article ID e1000371, 2009.

[135] P. Loke, A. S. MacDonald, and J. E. Allen, "Antigen-presenting cells recruited by Brugia malayi induce Th2 differentiation of naive CD4(+) T cells," European Journal of Immunology, vol. 30, no. 4, pp. 1127-1135, 2000.

[136] S. Babu, V. Kumaraswami, and T. B. Nutman, "Alternatively activated and immunoregulatory monocytes in human filarial infections," Journal of Infectious Diseases, vol. 199, no. 12, pp. 1827-1837, 2009.

[137] D. M. Mosser and J. P. Edwards, "Exploring the full spectrum of macrophage activation," Nature Reviews Immunology, vol. 8, no. 12, pp. 958-969, 2008.

[138] M. Munder, F. Mollinedo, J. Calafat et al., "Arginase I is constitutively expressed in human granulocytes and participates in fungicidal activity," Blood, vol. 105, no. 6, pp. 2549-2556, 2005.

[139] G. Raes, R. Van Den Bergh, P. De Baetselier et al., "Arginase1 and Ym1 are markers for murine, but not human, alternatively activated myeloid cells," Journal of Immunology, vol. 174, no. 11, pp. 6561-6562, 2005.

[140] J. E. Allen, R. A. Lawrence, and R. M. Maizels, "APC from mice harbouring the filarial nematode, Brugia malayi, prevent cellular proliferation but not cytokine production," International Immunology, vol. 8, no. 1, pp. 143-151, 1996.

[141] P. Loke, A. S. MacDonald, A. Robb et al., "Alternatively activated macrophages induced by nematode infection inhibit proliferation via cell-to-cell contact," European Journal of Immunology, vol. 30, no. 9, pp. 2669-2678, 2000.

[142] D. R. Herbert, T. Orekov, A. Roloson et al., "Arginase I suppresses IL-12/IL-23p40-driven intestinal inflammation during acute schistosomiasis," Journal of Immunology, vol. 184, no. 11, pp. 6438-6446, 2010.

[143] A. Zhao, J. F. Urban Jr., R. M. Anthony et al., "Th2 cytokine-induced alterations in intestinal smooth muscle function depend on alternatively activated macrophages," Gastroenterology, vol. 135, no. 1, article e211, pp. 217-225, 2008.

[144] M. G. Nair, Y. Du, J. G. Perrigoue et al., "Alternatively activated macrophage-derived RELM- $\alpha$ is a negative regulator of type 2 inflammation in the lung," Journal of Experimental Medicine, vol. 206, no. 4, pp. 937-952, 2009.

[145] J. T. Pesce, T. R. Ramalingam, M. S. Wilson et al., "Retnla (relmalpha/fizz1) suppresses helminth-induced Th2-type immunity," PLoS Pathogens, vol. 5, no. 4, Article ID e1000393, 2009.

[146] M. S. Wilson and R. M. Maizels, "Regulatory T cells induced by parasites and the modulation of allergic responses," Chemical Immunology and Allergy, vol. 90, pp. 176-195, 2006.

[147] K. J. Else, "Have gastrointestinal nematodes outwitted the immune system?” Parasite Immunology, vol. 27, no. 10-11, pp. 407-415, 2005.

[148] M. Hesse, C. A. Piccirillo, Y. Belkaid et al., "The pathogenesis of schistosomiasis is controlled by cooperating IL-10producing innate effector and regulatory T cells," Journal of Immunology, vol. 172, no. 5, pp. 3157-3166, 2004.
[149] A. S. McKee and E. J. Pearce, "CD25+CD4+ cells contribute to Th2 polarization during helminth infection by suppressing Th1 response development," Journal of Immunology, vol. 173, no. 2, pp. 1224-1231, 2004.

[150] J. J. Taylor, M. Mohrs, and E. J. Pearce, "Regulatory T cell responses develop in parallel to Th responses and control the magnitude and phenotype of the Th effector population," Journal of Immunology, vol. 176, no. 10, pp. 5839-5847, 2006.

[151] S. Metenou, B. Dembele, S. Konate et al., "At homeostasis filarial infections have expanded adaptive $\mathrm{T}$ regulatory but not classical Th2 cells," Journal of Immunology, vol. 184, no. 9, pp. 5375-5382, 2010.

[152] S. Rausch, J. Huehn, D. Kirchhoff et al., "Functional analysis of effector and regulatory $\mathrm{T}$ cells in a parasitic nematode infection," Infection and Immunity, vol. 76, no. 5, pp. 19081919, 2008

[153] S. Rausch, J. Huehn, C. Loddenkemper et al., "Establishment of nematode infection despite increased Th2 responses and immunopathology after selective depletion of Foxp3+ cells," European Journal of Immunology, vol. 39, no. 11, pp. 30663077, 2009.

[154] N. Harris and W. C. Gause, "To B or not to B: B cells and the Th2-type immune response to helminths," Trends in Immunology, vol. 32, no. 2, pp. 80-88, 2010.

[155] H. J. Hernandez, Y. Wang, and M. J. Stadecker, "In infection with Schistosoma mansoni, B cells are required for T helper type 2 cell responses but not for granuloma formation," Journal of Immunology, vol. 158, no. 10, pp. 4832-4837, 1997.

[156] D. Jankovic, A. W. Cheever, M. C. Kullberg et al., "CD4+ T cell-mediated granulomatous pathology in schistosomiasis is downregulated by a B cell-dependent mechanism requiring Fc receptor signaling," Journal of Experimental Medicine, vol. 187, no. 4, pp. 619-629, 1998.

[157] T. Adjobimey and A. Hoerauf, "Induction of immunoglobulin G4 in human filariasis: an indicator of immunoregulation," Annals of Tropical Medicine and Parasitology, vol. 104, no. 6, pp. 455-464, 2010.

[158] E. A. Ottesen, F. Skvaril, S. P. Tripathy et al., "Prominence of IgG4 in the IgG antibody response to human filariasis," Journal of Immunology, vol. 134, no. 4, pp. 2707-2712, 1985.

[159] R. Hussain, R. G. Hamilton, V. Kumaraswami et al., "IgE responses in human filariasis. I. Quantitation of filariaspecific IgE," Journal of Immunology, vol. 127, no. 4, pp. 1623-1629, 1981.

[160] R. A. Lawrence, "Immunity to filarial nematodes," Veterinary Parasitology, vol. 100, no. 1-2, pp. 33-44, 2001.

[161] J. S. van der Zee, P. van Swieten, and R. C. Aalberse, "Inhibition of complement activation by IgG4 antibodies," Clinical and Experimental Allergy, vol. 64, no. 2, pp. 415-422, 1986.

[162] L. Hussaarts, L. E. van der Vlugt, M. Yazdanbakhsh et al., "Regulatory B-cell induction by helminths: implications for allergic disease," Journal of Allergy and Clinical Immunology. In press.

[163] S. Amu, S. P. Saunders, M. Kronenberg et al., "Regulatory $B$ cells prevent and reverse allergic airway inflammation via FoxP3-positive T regulatory cells in a murine model," Journal of Allergy and Clinical Immunology, vol. 125, no. 5, article e1118, pp. 1114-1124, 2010.

[164] S. Hartmann, C. Schnoeller, A. Dahten et al., "Gastrointestinal nematode infection interferes with experimental allergic airway inflammation but not atopic dermatitis," Clinical and Experimental Allergy, vol. 39, no. 10, pp. 1585-1596, 2009. 
[165] N. Gomez-Escobar, E. Lewis, and R. M. Maizels, "A novel member of the transforming growth factor- $\beta$ (TGF- $\beta$ ) superfamily from the filarial nematodes Brugia malay $i$ and $B$. pahangi," Experimental Parasitology, vol. 88, no. 3, pp. 200 209, 1998.

[166] S. J. Davies, C. B. Shoemaker, and E. J. Pearce, "A divergent member of the transforming growth factor $\beta$ receptor family from Schistosoma mansoni is expressed on the parasite surface membrane," Journal of Biological Chemistry, vol. 273, no. 18, pp. 11234-11240, 1998.

[167] M. J. Beall and E. J. Pearce, "Human Transforming Growth Factor- $\beta$ Activates a Receptor Serine/Threonine Kinase from the Intravascular Parasite Schistosoma mansoni," Journal of Biological Chemistry, vol. 276, no. 34, pp. 31613-31619, 2001.

[168] J. L. Pennock, J. M. Behnke, Q. D. Bickle et al., "Rapid purification and characterization of L-dopachrome-methyl ester tautomerase (macrophage-migration-inhibitory factor) from Trichinella spiralis, Trichuris muris and Brugia pahangi," Biochemical Journal, vol. 335, no. 3, pp. 495-498, 1998.

[169] J. J. Vermeire, Y. Cho, E. Lolis et al., "Orthologs of macrophage migration inhibitory factor from parasitic nematodes," Trends in Parasitology, vol. 24, no. 8, pp. 355-363, 2008.

[170] X. Zang, P. Taylor, J. M. Wang et al., "Homologues of human macrophage migration inhibitory factor from a parasitic nematode: Gene cloning, protein activity, and crystal structure," Journal of Biological Chemistry, vol. 277, no. 46, pp. 44261-44267, 2002.

[171] C. Klotz, T. Ziegler, E. Daniłowicz-Luebert et al., "Cystatins of parasitic organisms," Advances in Experimental Medicine and Biology, vol. 712, pp. 208-221, 2011.

[172] T. Dainichi, Y. Maekawa, K. Ishii et al., "Molecular cloning of a cystatin from parasitic intestinal nematode, Nippostrongylus brasiliensis," The Journal of Medical Investigation, vol. 48, no. 1-2, pp. 81-87, 2001.

[173] X. Zang, M. Yazdanbakhsh, H. Jiang et al., "A novel serpin expressed by blood-borne microfilariae of the parasitic nematode Brugia malayi inhibits human neutrophil serine proteinases," Blood, vol. 94, no. 4, pp. 1418-1428, 1999.

[174] P. Stanley and P. E. Stein, "BmSPN2, a serpin secreted by the filarial nematode Brugia malayi, does not inhibit human neutrophil proteinases but plays a noninhibitory role," Biochemistry, vol. 42, no. 20, pp. 6241-6248, 2003.

[175] W. Harnett, I. B. McInnes, and M. M. Harnett, "ES-62, a filarial nematode-derived immunomodulator with antiinflammatory potential," Immunology Letters, vol. 94, no. 1-2, pp. 27-33, 2004.

[176] M. M. Harnett, A. J. Melendez, and W. Harnett, "The therapeutic potential of the filarial nematode-derived immunodulator, ES-62 in inflammatory disease," Clinical and Experimental Immunology, vol. 159, no. 3, pp. 256-267, 2010.

[177] F. A. Marshall, K. A. Watson, P. Garside et al., "Effect of activated antigen-specific B cells on ES-62-mediated modulation of effector function of heterologous antigen-specific $\mathrm{T}$ cells in vivo," Immunology, vol. 123, no. 3, pp. 411-425, 2008.

[178] M. Okano, K. Nishizaki, M. Abe et al., "Strain-dependent induction of allergic rhinitis without adjuvant in mice," Allergy, vol. 54, no. 6, pp. 593-601, 1999.

[179] M. Wuhrer, C. I. Balog, M. I. Catalina et al., "IPSE/alpha1 , a major secretory glycoprotein antigen from schistosome eggs, expresses the Lewis X motif on core-difucosylated Nglycans," FEBS Journal, vol. 273, no. 10, pp. 2276-2292, 2006.
[180] M. Okano, A. R. Satoskar, K. Nishizaki et al., "Lacto-N-fucopentaose III found on Schistosoma mansoni egg antigens functions as adjuvant for proteins by inducing Th2-type response1," Journal of Immunology, vol. 167, no. 1, pp. 442450, 2001.

[181] R. R. Pires, T. M. Oshiro, D. M. Itami et al., "Production and characterization of a monoclonal antibody against an Ascaris suum allergenic component," Brazilian Journal of Medical and Biological Research, vol. 34, no. 8, pp. 1033-1036, 2001.

[182] T. M. Oshiro, A. Rafael, C. S. Enobe et al., "Comparison of different monoclonal antibodies against immunosuppresive proteins of Ascaris suum," Brazilian Journal of Medical and Biological Research, vol. 37, no. 2, pp. 223-226, 2004.

[183] S. T. Holgate and R. Polosa, "Treatment strategies for allergy and asthma," Nature Reviews Immunology, vol. 8, no. 3, pp. 218-230, 2008. 

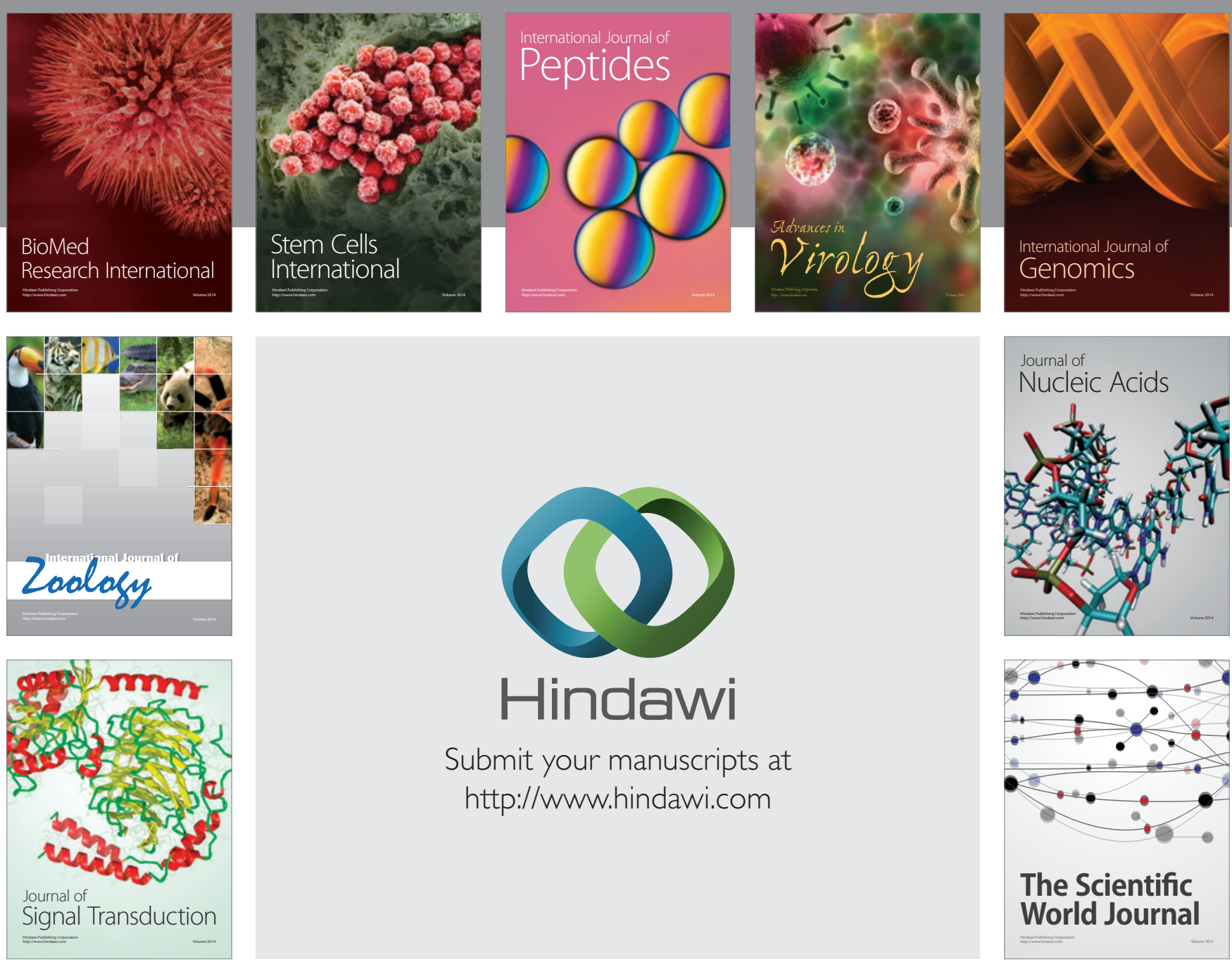

Submit your manuscripts at

http://www.hindawi.com
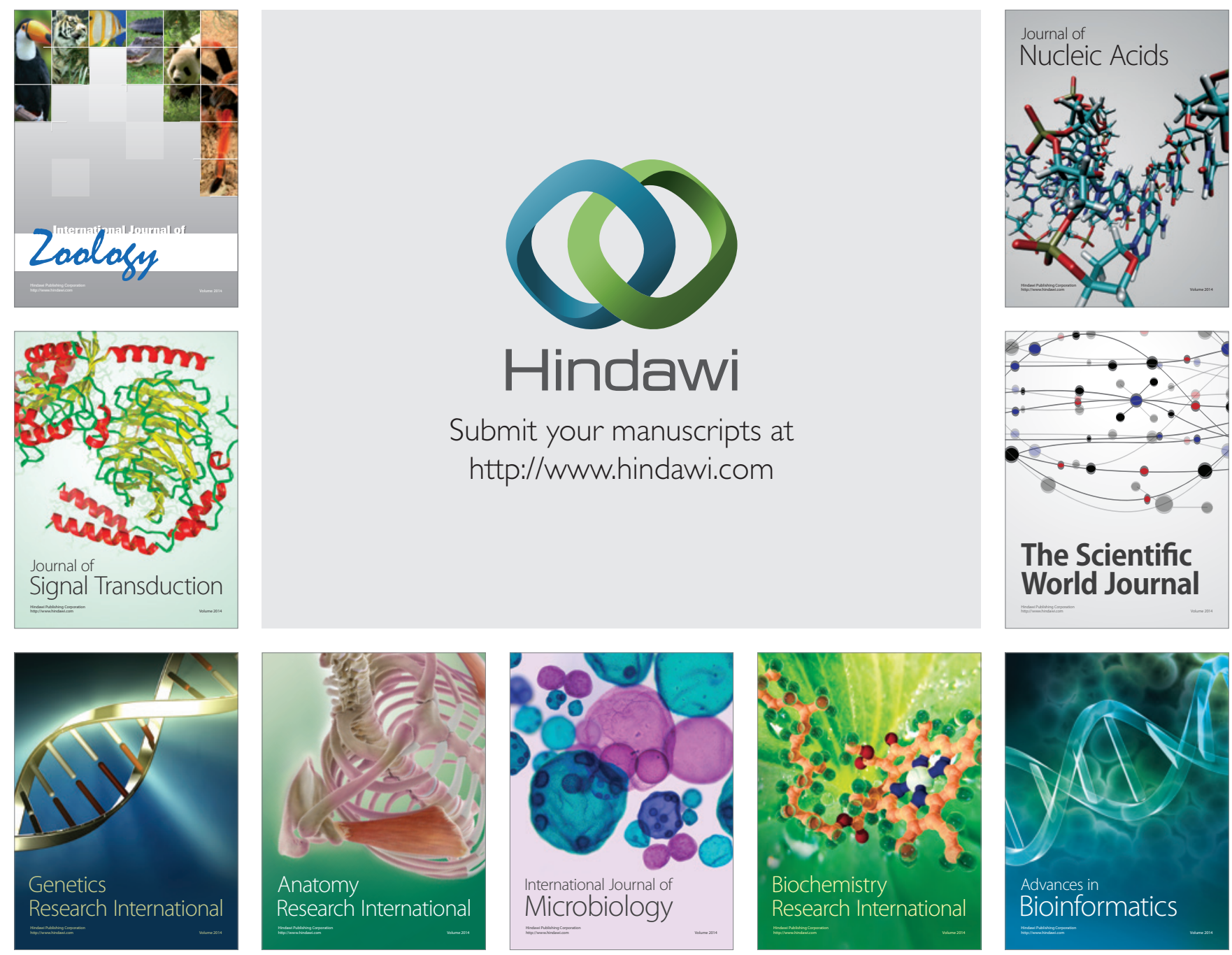

The Scientific World Journal
